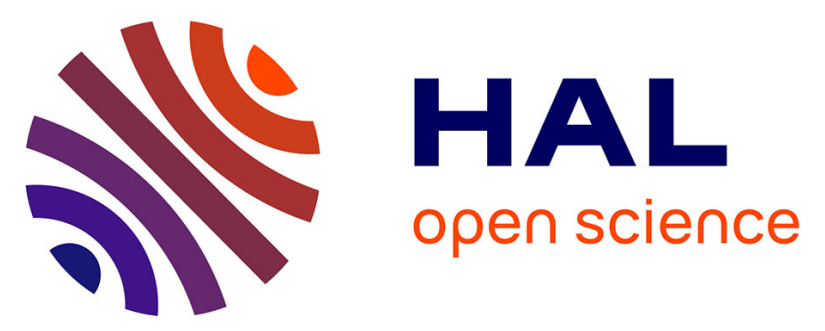

\title{
Ontogenetic and static allometry in the skull and cranial units of nine-banded armadillos (Cingulata: Dasypodidae: Dasypus novemcinctus)
}

\author{
Kévin Le Verger, Lionel Hautier, Jérémie Bardin, Sylvain Gerber, Frédéric \\ Delsuc, Guillaume Billet
}

\section{To cite this version:}

Kévin Le Verger, Lionel Hautier, Jérémie Bardin, Sylvain Gerber, Frédéric Delsuc, et al.. Ontogenetic and static allometry in the skull and cranial units of nine-banded armadillos (Cingulata: Dasypodidae: Dasypus novemcinctus). Biological Journal of the Linnean Society, 2020, 131 (3), pp.673-698. 10.1093/biolinnean/blaa083 . hal-02994330

\section{HAL Id: hal-02994330 \\ https://hal.science/hal-02994330}

Submitted on 2 Dec 2020

HAL is a multi-disciplinary open access archive for the deposit and dissemination of scientific research documents, whether they are published or not. The documents may come from teaching and research institutions in France or abroad, or from public or private research centers.
L'archive ouverte pluridisciplinaire $\mathbf{H A L}$, est destinée au dépôt et à la diffusion de documents scientifiques de niveau recherche, publiés ou non, émanant des établissements d'enseignement et de recherche français ou étrangers, des laboratoires publics ou privés. 
Title:

\section{Ontogenetic and static allometry in the skull and cranial units of nine-} banded armadillos (Cingulata: Dasypodidae: Dasypus novemcinctus)

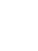

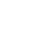
7 8

\section{KÉVIN LE VERGER ${ }^{1 *}$; LIONEL HAUTIER ${ }^{2,3}$; JÉRÉMIE BARDIN ${ }^{4}$; SYLVAIN} GERBER $^{5}$; FRÉDÉRIC DELSUC ${ }^{2}$, and GUILLAUME BILLET ${ }^{1}$

${ }^{1}$ Museum national d'Histoire naturelle, Centre de Recherche en Paléontologie - Paris, UMR 7207 CR2P MNHN/CNRS/UPMC, Sorbonne Universités, 8 rue Buffon, CP 38, 75005 Paris, France.

${ }^{2}$ Institut des Sciences de l'Evolution, Université de Montpellier, UMR 5554 ISEM

CNRS/IRD/EPHE, Place Eugène Bataillon, CC65, 34095 Montpellier cedex, France.

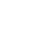

\footnotetext{
${ }^{3}$ Natural History Museum of London, Department of Life Sciences, Mammal Section, London, United Kingdom.
}

${ }^{4}$ Museum national d'Histoire naturelle, Centre de Recherche en Paléontologie - Paris, UMR 7207 CR2P MNHN/CNRS/UPMC, Sorbonne Universités, 4 place Jussieu, 75005 Paris, France. 
${ }^{5}$ Muséum national d'Histoire naturelle, Institut de Systématique, Évolution, Biodiversité, UMR 7205 ISYEB MNHN/CNRS/UPMC/EPHE, Sorbonne Universités, 45 rue Buffon, CP 50, 75005 Paris, France.

* Corresponding author: Kévin Le Verger; address: 8 rue Buffon, CP 38, 75005 Paris, France; telephone number: 01.40.79.53.79; fax number: 01.40.79.35.80. E-mail: kevin.leverger@edu.mnhn.fr.
ABSTRACT variation in size through allometric effects. Previous studies suggested that craniofacial allometry is the dominant pattern underlying mammalian skull shape variation, but cranial allometries were rarely characterized within cranial units such as individual bones. Here, we used 3D geometric morphometric methods to study allometric patterns of the whole skull (global) and of cranial units (local) in a postnatal developmental series of nine-banded armadillos (Dasypus novemcinctus ssp.). Analyses were conducted at the ontogenetic and static levels, and for successive developmental stages. Our results support craniofacial allometry as the global pattern along with more local allometric trends, such as the relative posterior elongation of the infraorbital canal, the tooth row reduction on the maxillary, and the marked development of nuchal crests on the supraoccipital with increasing skull size. Our study also reports allometric proportions of shape variation varying substantially among cranial units and across ontogenetic stages. The multi-scale approach advocated here allowed unveiling previously unnoticed allometric variations, indicating an untapped complexity of cranial allometric patterns to further explain mammalian morphological evolution. 
KEYWORDS: Geometric morphometrics - Shape - Cranial bones - Size variation -

Development - Armadillos - Xenarthra - Allometry.

\section{INTRODUCTION}

Variation in size is a major component of tetrapod evolution and diversity. Among them, mammals developed a wide range of body sizes since the onset of the Cenozoic era (Smith et al., 2010), with multiple independent events of size increase (Baker et al., 2015; Bokma et al.,

2016). The extant mammalian diversity extends over eight orders of magnitude in size (Price \& Hopkins, 2015), and this variation has accompanied ecological diversification (Sibly \& Brown, 2007; Price \& Hopkins, 2015). This size variation was also accompanied with major allometric trends during the course of mammalian evolution, particularly on the skull. Recent studies suggested that craniofacial allometry, i.e. larger faces relative to the rest of the skull in larger individuals, is a general evolutionary trend of morphological change in placentals, and possibly in other groups of vertebrates (Cardini \& Polly, 2013; Cardini, 2019; Linde-Medina, 2016). Craniofacial allometry is also observable intraspecifically in developmental series of extant mammals (Cardini \& Polly, 2013) but is absent in early diverging amniotes and in stem-mammals such as cynodonts (Hoffman \& Rowe, 2018). This shows that the craniofacial allometry might represent a mammal-specific trend at both the evolutionary and ontogenetic levels. Other common allometric aspects previously suggested in the mammalian skull, and generally based on bivariate analyses, include the negative allometry of middle-ear ossicles relative to the skull dimensions (e.g., Nummela, 1995), the negative allometry of the inner ear relative to the petrosal (Billet et al., 2015), and more generally the negative allometry of sense organs relative to other skull parts (e.g., Sánchez-Villagra, 2012). 
Many recent studies analysed cranial allometry in mammalian species using 3D

geometric morphometrics methods (GMM) in relation to functional morphology, phylogeny or cranial integration (Marroig \& Cheverud, 2004; Slater \& Van Valkenburgh, 2009; Hautier et al., 2017; Cardini, 2019). Most of these GMM studies considered the entire skull, and only a few of them touched upon this concept using an atomistic approach, i.e. focusing on more specific anatomical regions. Although it lacks the 3D approach of GMM, the use of linear distances showed on several instances that large cranial regions display different allometries relative to the entire skull (Slijper, 1962; Monteiro et al., 1999; Ross \& Metzger, 2004; Marroig \& Cheverud, 2004). These studies have highlighted complex allometric trends on the mammalian skull, which are likely determined by multiple and interacting developmental processes (Hallgrímsson et al., 2019). In fact, much remains to be discovered about these complex morphological patterns especially in the way that allometric growth differentially affects the various parts of the skull and induces cranial shape changes during ontogeny.

Armadillos have been poorly studied regarding allometry despite the fact that the group experienced a spectacular body mass increase in some lineages, especially in glyptodonts (Delsuc et al., 2016). The smallest armadillo species do not exceed $0.115 \mathrm{~kg}$ while some glyptodonts weighed more than 2,000 kg (Superina \& Abba, 2018; Vizcaíno et al., 2012). Size was generally treated separately from other biological traits in taxonomic or evolutionary contributions on this group (e.g., Wetzel \& Mondolfi, 1979), while other studies addressed allometry in the postcranial skeleton of armadillos from the functional, metabolic or physiological viewpoints (e.g., Frappell et al., 1998; Vizcaíno \& Milne, 2002; Costa et al., 2019). However, Cardini (2019) demonstrated that extant armadillos exhibit a craniofacial evolutionary allometry similar to that of other placental mammals, a trend also detected in a comparative investigation of allometric variations between several armadillo genera (Moeller, 1968) and in two more detailed studies on euphractines (Abba et al., 2015) and dasypodines 
(Hautier et al., 2017). Apart from craniofacial allometry, no other quantitative analysis of cranial allometry exists for armadillos and no cranial shape change related to size was described in the group.

Our study focuses on describing ontogenetic and static allometric patterns in the skull of the most common, best studied, and widely distributed extant cingulate: the nine-banded armadillo (Dasypus novemcinctus ssp. Linnaeus, 1758). Being distributed on the two American continents, this taxon can be split in as much as four different geographical morphotypes, some or all of which may represent distinct species or subspecies: Southern, Central, Northern, and Guianan (Billet et al., 2017; Hautier et al., 2017), as also suggested by molecular studies based on mitochondrial markers (Huchon et al., 1999; Gibb et al., 2016; Feijó et al., 2018, 2019; Arteaga et al., 2020). Based on a large sample covering three of these four morphotypes, our study aims at understanding how allometric variation is distributed in their skull and seeks to further characterize the covariation between shape and size across different cranial units, while controlling for potential effects of geography. More precisely, we analysed allometry in: i) the entire skull, and ii) virtually isolated cranial units, looking at both ontogenetic and static allometry. We report heterogeneous cranial allometric patterns in time and space and discuss potential underlying processes.

\section{MATERIAL AND METHODS}

\section{SAMPLING}

We sampled 96 cranial specimens stored in the collections of the Muséum national d'Histoire naturelle (MNHN, collections Zoologie et Anatomie comparée, Mammifères et Oiseaux) in Paris (France), the Natural History Museum (BMNH) in London (UK), the Museum of Natural Science of the Louisiana State University (LSU) in Baton Rouge (USA), the 
American Museum of Natural History (AMNH) in New York (USA), the National Museum of Natural History (NMNH) in Washington (USA) and the Muséum d'Histoire Naturelle in Geneva (MHNG, Switzerland) (see Table S1 for a complete list of specimens). The sample is largely similar to that of Hautier et al. (2017), although some specimens could not be considered here, as they were too incomplete for the proposed set of landmarks (see below). We also added new specimens to complete the ontogenetic series (details available in Table S1). In order to minimize phylogenetic effects, we did not include specimens belonging to the “Guianan morphotype” (Hautier et al., 2017; Billet et al., 2017) as recent morpho-anatomical and molecular studies considered it to be clearly distinct from other D. novemcinctus populations, and to likely represent a new species (Huchon et al., 1999; Gibb et al., 2016; Billet et al., 2017; Hautier et al., 2017; Feijó et al., 2018, 2019; Arteaga et al., 2020). These studies have also shown that other morphotypes recognizable within $D$. novemcinctus may represent sub-species or even distinct species, hence our use of D. novemcinctus ssp. to refer to this potential species complex. Pending more definite conclusions on these aspects, the northern, central, and southern morphotypes were included together in our study and their distribution systematically scrutinized within the allometric analyses. In addition, all analyses of ontogenetic allometry were performed on two different datasets for comparison: on the whole sample and on the best-sampled morphotype only (i.e. southern; $n=48$ ). Finally, potential differences between allometric trajectories among morphotypes were also tested. No specimen belonging to the hairy long-nosed armadillo (Dasypus pilosus) was included in the study as it is very divergent morphologically, although recent molecular studies have shown that this species may also be part of the Dasypus novemcinctus ssp. complex (Gibb et al., 2016; Feijó et al., 2019). 

(France), at the Natural History Museum (BMNH), and at the AST-RX platform of the Muséum national d'Histoire naturelle (MNHN). Image stacks were improved in contrast,

154 rotated, cropped, and reduced to 8 bits using the ImageJ software (Schneider et al., 2012). Three-dimensional reconstruction and visualization of the skulls and of the virtually isolated bones were performed using stacks of digital images with MIMICS v. 21.0 software (3D Medical Image Processing Software, Materialize, Leuven, Belgium). Cranial shapes were quantified with 131 anatomical landmarks (Fig. 1 and Table 1, 2, S2) placed on the exported 3D models using AVIZO v. 9.7.0 software (Visualization Sciences Group, Burlington, MA, USA). The landmarks corresponding to external cranial structures were based on wellestablished landmark sets from previous studies on mammalian taxa (Goswami \& Finarelli, 2016; Hautier et al., 2017), and new landmarks were added on internal structures. Landmarks were selected to provide a good overall representation of skull shape, isolated bones, and characters traditionally used in cingulate phylogenetic analyses of the group (Gaudin \& Wible, 2006; Billet et al., 2011). The last criterion was set for future studies aiming at integrating knowledge on allometry and covariation patterns for the construction of phylogenetic characters. All landmarks were positioned on suture contacts or at the maximum of curvature, or extreme points of bony processes, fossae or foramina except for landmark \#131 (Fig. 1), which corresponds to the dorsal projection of the most posterior point of the frontal sinuses (see Billet et al., 2017) on the midline in dorsal view (it was landmarked with the transparency option in Avizo). This point was added to the landmark set in order to include an anatomical landmark on the large dorsal exposure of the frontal bone. We then performed a generalized Procrustes analysis (Rohlf \& Slice, 1990) using function gpagen in the R package geomorph version 3.1.0 (Adams et al., 2019), and intra-individual asymmetries (Klingenberg et al., 2002) were removed using the function symmetrize in the R package 
Morpho version 2.6 (Schlager, 2017). When some landmarks were missing on one side of the skull, their position was estimated using the function fixLMmirror in the Morpho R package (see Table S3). The logarithm of the centroid size was used as a size variable for the different cranial structures.

\section{DETERMINATION OF ONTOGENETIC STAGES}

The determination of the developmental stage of each specimen was based on dental eruption, cranial ossification and cranial length. Except for size, these variables were each composed of various discrete observations scored numerically. The scored observations were then averaged to be compiled in a dental eruption index and a cranial ossification index. The observations on dental eruption were made on CT-images and on 3D reconstructions of the skulls and corresponded to the number of teeth present, as well as their class and generation. Based on our observations of the upper dentition, we defined five dental stages. Concerning the ossification, only bones whose suture closure vary along our ontogenetic series were scored. The cranial length value (LTC - measure taken between landmarks \#1 and \#84) used for this analysis was directly sourced from the work of Hautier et al. (2017). The combination of these three variables allowed confirming the ontogenetic separation of specimens in five stages. Some specimens could not be allocated to a particular stage because they preserved no teeth. In this case, these specimens were not included in the analyses where information on ontogenetic stage was needed (see Supplementary Information 1, Figs. S1-3, Table S4, S5 for details of the protocol and results concerning the determination of ontogenetic stages).

Only complete specimens $(n=76$, Table S1) were included in the analyses of allometry performed on the entire skull (ES). The ES Procrustes alignment was realized on the entire set 
of cranial landmarks, including both sides of the skull. For the ES analysis of ontogenetic allometry, the whole sample corresponds to 76 specimens with 48 specimens belonging to the "Southern group", 11 specimens to the "Central group", and 17 specimens to the "Northern group" as defined by Hautier et al. (2017) and Billet et al. (2017). Only adult specimens were considered in the ES analysis of static allometry (i.e., 51 specimens in total, with 35 from the Southern, five from the Central, and 11 from the Northern groups). Under the Bone-By-Bone (3B) approach, the analysed objects corresponded to a virtually isolated bone or group of bones that we defined in this study as Operational Bone Units (OBUs). We used the same samples for both the ES and 3B analyses of allometry $(\mathrm{n}=$ 76 for ontogenetic allometry; $n=51$ for static allometry). Each 3B Procrustes alignment was realized on a reduced set of landmarks corresponding to the OBU under consideration. The allometric component in the shape variation of OBUs was analysed using the skull centroid size as a measure of size. We performed the 3B analyses only on the left cranial side, which was more complete in most cases. These $3 \mathrm{~B}$ analyses were only performed on one side since many paired bones were not contiguous and to avoid taking into account symmetrized bones: premaxillary (pmx); maxillary (mx); nasal (na); frontal (fr); lacrimal (lac); jugal (ju); palatine (pal); parietal (pa); squamosal (sq); supraoccipital (so); petrosal (pe). Two OBUs corresponding to bone complexes (alisphenoid-orbitosphenoid-pterygoid-basisphenoid, as-ospt-bs; basioccipital-exoccipital, bo-eo) were also defined as some of their bony components (alisphenoid-orbitosphenoid; basioccipital-exoccipital) were often fused in adults, and because only OBUs represented by more than three landmarks could be considered. In the whole landmark dataset, only landmark \#114 was not included in the 3B approach as it could not be associated with any of the 13 OBUs. 
For both the ES and 3B analyses of allometry, we performed a multivariate regression of Procrustes shape coordinates (Izenman, 2013) on size (log Centroid Size) using the function procD.lm of the $\mathrm{R}$ package geomorph. The $R^{2}$ (coefficient of determination) of these analyses represents the percentage of the total shape variation explained by the independent variable, here size (Goodall, 1991; Klingenberg \& McIntyre, 1998; Drake \& Klingenberg, 2008). We referred to this percentage as the "allometric proportion of the total shape variation". We assessed the statistical significance of the regressions against the null hypothesis of isometric variation using permutation tests with 10,000 iterations (Good, 2000). We also present the values for the $R^{2}$ of non-significant regressions (at $p$-value $>0.05$ ) and comment them cautiously following recent recommendations by Dushoff et al. (2019).

\section{COMMON ALLOMETRY AMONG MORPHOTYPES}

For the ES approach, differences in allometric trajectories among morphotypes at the ontogenetic and static levels were investigated. For this analysis, we performed a HOS (Homogeneity of Slope Test) using a Procrustes ANOVA (Goodall, 1991) for morphotypes, size, and interaction between both variables (Collyer \& Adams, 2013). The HOS performs statistical assessment of the terms in the model using Procrustes distances among specimens, rather than explained covariance matrices among variables, which is equivalent to distancebased ANOVA designs (Anderson, 2001). The HOS calculates the amount of shape variation explained by size, computes the allometric slopes for each category of the independent variable, and quantifies the influence of a given factor on the shape variation. Statistical significance was evaluated with a residual randomization permutation procedure with 10,000 iterations (Collyer et al., 2015). If the null hypothesis of HOS (= parallel slopes) is rejected, then morphotypes differ in their patterns of allometric growth. The HOS analysis was conducted using the procD.allometry function of the geomorph package version 3.0.7 (Adams 
et al., 2018). More precisely, these analyses were performed to identify the interaction between geographic distribution (morphotypes) and allometry on shape variation by including pairwise comparisons between groups (distribution) to assess significant differences of both the direction (angles) and magnitude (amount of change in shape with size) of allometric trajectories. The pairwise comparisons were performed with advanced.procD.lm from the geomorph package version 3.0.7. When trajectories significantly differed between morphotypes, allometric patterns were analyzed both within the whole sample and within the southern morphotype subsample only.

\section{COMMON ALLOMETRY BETWEEN ONTOGENETIC STAGES}

Multivariate regressions of shape on the logarithm of the skull centroid size were also performed for the different ontogenetic stages determined (see Results) in order to compare the allometric proportions between stages for a given OBU. We then tested the allometric differences between each ontogenetic stage for a given OBU. This preliminary investigation could not be conducted within particular morphotypes because their sampling per ontogenetic stage for each was too low. For this analysis, we performed also a HOS test using a Procrustes ANOVA on each OBU for ontogenetic stage, size, and interaction between both variables. In order to reduce biases linked to sample size, we calculated the angles of each slope for a given OBU versus the horizontal axis to test whether the different ontogenetic stages for a given OBU share a common allometry (see Klingenberg, 2016). The ratio between the OBU relative size and its average for a given ontogenetic stage was also calculated for each stage and for the entire sample in order to analyse the growth dynamics of the OBU.

\section{RESULTS}


The regression of shape on log centroid size in our ontogenetic series of D. novemcinctus ssp. accounts for $27.62 \%$ of the total shape variation ( $p$-value $<0.0001$, Figs. 2 ; S4). The geographical distribution explains $16.64 \%$ of the total shape variation ( $p$-value $<0.0001$, Fig. S4). At the ontogenetic level, the morphotypes show a slight difference in their allometric trajectory attesting to an interaction between geography and allometry on shape variation during ontogeny (Fig. S4). However, this effect seems to be minimal (3.16 \%; Fig. S4). The HOS test pairwise comparisons of ontogenetic allometric trajectories suggests no difference between the Central and Southern morphotypes, but a significant difference between the latter two and the Northern morphotype. These results should be taken with caution as the p-value is very close to the statistically significance threshold in the comparison between the Central and Southern morphotypes $(=0.0515)$ and the difference revealed with the Northern morphotype may be due to the lack of specimens as young as for the other two morphotypes. Because these results suggest that the ontogenetic allometries may slightly differ among morphotypes, the allometric shape changes during ontogeny were analyzed both within the whole sample (see below) and within the Southern morphotype subsample (Fig. S5).

The regression of shape on the logarithm of the centroid size in our adult sample of $D$. novemcinctus ssp. accounts for only $6.31 \%$ of the total shape variation ( $p$-value $<0.0001$, Figs. 2; S4). The effect of geographical distribution is proportionally higher, expressing $22.81 \%$ of the total shape variation ( $p$-value $<0.0001$, Fig. S4). At the static level, the morphotypes share a common allometric trajectory and no interaction between geography and allometry is statistically supported, although the $p$-value is close to the significance threshold $(p$-value $=0.0619)$. It should also be noted that the central morphotype has relatively low sample size (Fig. S4). The HOS test pairwise comparisons of static allometric trajectories suggests no difference between each morphotype. Because these results suggest that the static 
allometries are similar among morphotypes, the allometric shape changes at the adult stage were analyzed within the whole sample only (see below).

\section{ALLOMETRIC VARIATIONS ON THE ENTIRE SKULL (ES)}

\section{Ontogenetic allometry}

Three main regional trends of skull allometric variation can be recognized in our ontogenetic series. Adult cranial proportions clearly differed from juvenile ones in the relative size of the snout and zygomatic arches compared to the braincase (Fig. 2A; Table S6). The snout undergoes an anteroposterior elongation with size increase. This elongation is bidirectional (one directed anteriorly and the other posteriorly) and has different magnitudes of variation depending on the landmarks considered. Most of the landmarks of the anterior tip of the snout $(\# 1 ; \# 3-20)$ and the ones delineating the posterior end of the premolar row (\#29-30), show an anterior displacement relative to other landmarks during growth. On the other hand, most landmarks of the snout posterior to the premaxillary and nasal display a posterior directed elongation relative to the other landmarks. In addition to this elongation, the posterior end of the snout (i.e., delimited anteriorly by the most anterior point of the zygomatic arches) narrows in larger specimens, especially at the level of the infra-orbital and maxillary foramina. The zygomatic arches extend more ventrally and the temporal fenestra widen considerably as the size increases, as expressed by the vectors associated to landmarks \#22-23 and \#51-52, and by the increase of the post-orbital constriction (\#41-42). In the posterior half of the skull, most of landmark displacements are directed towards the centre of the braincase. During ontogeny, the proportions of the neurocranium decreases relative to the rest of the skull due to allometric growth. More local allometric changes are also highlighted: the landmark located at the posterior edge of the frontal sinuses (\#131) is particularly distinctive for its strong relative posterior displacement. The dental row is relatively shorter in larger 
specimens, with an anterior displacement of the posterior portion of the dental row (\#29-30) while the anterior portion varies very slightly (\#27-28). The analysis of the ES ontogenetic allometry in the southern morphotype revealed remarkably similar shape changes to the ones described above (Fig. S5).

\section{Static allometry}

An increase in size, at the static level, is only associated with minor shape variations of the skull (Fig. 2B; Table S6), similar to the pattern detected with the ontogenetic analyses of allometry, albeit to a lesser degree and with some variations specific to this level (see below). The most anterior part of the nasal bone shows a relative anterior displacement, just like the W-shaped processes in front of the premaxillary (as defined by landmarks \#8; \#11-14; Fig. 1). The rest of the face shows a relative narrowing as size increases. The shape changes of the zygomatic arches (slightly increasing width) are less strong than in the ontogenetic allometry analyses. The reduction in the relative proportions of the braincase is more pronounced for landmarks located on the cranial roof (frontal and parietal midline landmarks (\#113; \#114; \#131)) and the zygomatic-pterygoid region. The anterior border of the orbit widens as the post-orbital constriction becomes stronger with size. Strikingly, the landmark located on the maxillary-palatine suture (\#21) strongly moves forward in comparison to other surrounding landmarks as size increases, much more than in the ontogenetic analysis. A very strong anterior (\#19-21; \#45-46) and weak posterior (\#32) relative elongation of the palatine is detected at the static level. For all other landmarks, the allometric changes appear very weak when compared to their changes in the analysis of ontogenetic allometry.

\section{ALLOMETRIC VARIATIONS STUDIED BONE BY BONE (3B)}

Comparison between $O B U s$ 
We observe differences in the proportions of allometric shape variation between different OBUs both at the ontogenetic and static levels. In both cases (Fig. 3), the regression of shape on size shows no statistical support for the lacrimal (Fig. 3; Table 3; Figs. S6-7). This is not the case for other OBUs, for which at least the analyses at the ontogenetic level show a significant allometric effect. At the ontogenetic level, the premaxillary has the lowest proportion of shape variation explained by size of all OBUs (lacrimal excluded; Fig. 3A and Table 3). The jugal, petrosal, parietal, as-os-pt-bs OBU, nasal, palatine have a proportion of shape variation explained by size varying between $5 \%$ and $10 \%$ (Fig. $3 \mathrm{~A}$ and Table 3 ). The maxillary, supraoccipital and squamosal show allometric proportions between $10 \%$ and $12 \%$ (Fig. 3A and Table 3). Finally, the last two OBUs showing the highest proportion of variation explained by size at the ontogenetic level are the bo-eo OBU and the frontal, the latter with more than twice the proportion values find in the other OBUs (Fig. 3A and Table 3). At the static level, the allometric proportion is much lower than at the ontogenetic level for most OBUs. Only five OBUs show a statistically well-supported allometric effect at this level. Among them, the petrosal and the as-os-pt-bs OBU show an allometric proportion lower than 5\% (Fig. 3B and Table 3). The frontal shows a drastic reduction in its allometric proportion (5.96\%) (Fig. 3B and Table 3). Finally, the parietal and palatine have an allometric proportion almost equivalent to that obtained at the ontogenetic level - for the palatine, it is even higher to that of the entire skull (Fig. 3B and Table 3).

All descriptions of the allometric shape changes below describe the maximal shapes as compared to the minimal shapes per OBU at the ontogenetic level. This was done only for the OBUs whose allometric variation is statistically well-supported ( $p$-value $<0.05$ ). Only landmarks on the left side of the skull are mentioned (see Table 1 and Table 2 for their symmetrical landmark/counterparts). The same analyses were performed using the Southern 
morphotype only. We obtained very similar results (Fig. S5) as the ones described hereafter for the entire dataset. The only notable differences are generally in the norm (i.e. lesser) of the vectors and not in their direction. The results and shape changes explained by size for the static level on the whole sample are illustrated in Fig. S8 and those changes that differ from the ontogenetic level are described in Supplementary Information 2.

\section{Alisphenoid-Orbitosphenoid-Pterygoid-Basisphenoid complex (Fig. 4A1-A3)}

When the skull size increases, the foramen ovale (\#70) shows very little variation, while the transverse canal foramen (\#68) takes a more medial position. The pterygoid wings (\#66) are more extended posteriorly. The optical foramen is located more dorsolaterally (\#75). Internally, the most lateral point of the dorsal transverse ridge (\#130), which delimits the ethmoidal fossa anteriorly, is more laterally positioned. Finally, the contact between the frontal, the squamosal, and the alisphenoid (\#44) is located much more anteromedially.

As size increases, the basioccipital becomes mediolaterally wider (\#90). The concavity that constitutes the posterior part of the jugular foramen is less marked (\#96). The occipital condyles are relatively larger and more anterolaterally oriented (\#92; \#100). The foramen magnum (\#92; \#101) is relatively narrower mediolaterally, its ventral portion being more ventral. The exoccipital meets the supraoccipital much further dorsoanteriorly (\#94).

\section{Basioccipital-Exoccipital complex (Fig. 4B1-B3)}

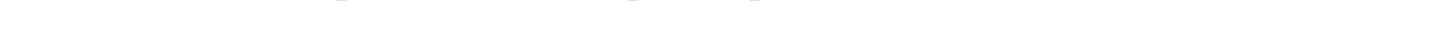

The allometric changes mainly involve the posterior development of the frontal sinuses (\#131), the deepening of the post-orbital constriction (\#42), and a more posteroventral location of the ventral intersection of the annular ring and cribriform plate (\#113). While the 
frontal sinuses are poorly developed in the juvenile stage, they extend much farther posteriorly in older specimens (see also Billet et al., 2017). The anterior part of the frontal extends further anteriorly in larger individuals (\#2; \#34; \#36) while its posterior part is relatively shortened anteroposteriorly and compressed dorsoventrally, as expressed by the landmarks $\# 44, \# 78$, and $\# 81$. Finally, the anterior edge of the orbit is placed only slightly more medially (\#38).

\section{Jugal (Fig. 4D1-D3)}

Two main allometric trends can be recognized for the jugal. Its anterior part, in contact with the lacrimal and the maxillary (\#50), shows a relative shortening as size increases. The second trend corresponds to a dorsoventral increase of the zygomatic arch $(\# 23$; \#54; \#56), which is stronger in its anteroventral and posterodorsal parts.

\section{Maxillary (Fig. 4E1-E3)}

From the juvenile stage to the adult stage, the maxillary shows a relative anterior elongation as shown by the landmarks in contact with the premaxillary (\#4; \#5; \#7), especially ventrally at the level of the midline. The landmarks in contact with the palatine (\#19; \#21) are shifted anterodorsally and the dorsal part of the snout (\#34; \#36) more posteroventrally. While the maxillary is bulging in its dorsal mid-part in juveniles, it is much shorter dorsoventrally in larger specimens, as marked by the landmark in contact with the nasal and the frontal (\#34). Large specimens also display a proportionally reduced dental row (\#29; \#31). The zygomatic process of the maxillary shows a more ventrolateral position (\#23). Finally, the relative length of the infraorbital canal varies strongly from juveniles to adults, the maxillary foramen being more posterior in larger specimens, as expressed by the landmark \#25. 
The nasal is relatively narrower mediolaterally in larger specimens with a much more pronounced internal curvature. Only the landmarks in contact with the premaxillary (\#4; \#10) show a slight anterior elongation in the medial part of the bone.

\section{Palatine (Fig. 5G1-G3)}

The palatine becomes relatively more elongated anteroposteriorly and narrower mediolaterally as size increases. This elongation is particularly visible between the anterolateral edge of the palatine and the caudal palatine foramen that became more distant from one another as size increases (\#19; \#21; \#46).

\section{Parietal (Fig. 5H1-H3)}

The parietal is slightly more elongated anteroposteriorly and narrower mediolaterally in larger specimens (\#78; \#79; \#81; \#83). The tentorial process forms a higher ventrally-directed crest as size increases (\#73).

\section{Petrosal (Fig. 5I1-I3)}

On the promontorium, size has little effect on shape variation except at the anterior and medial borders, which are slightly more reduced as size increases (\#104; \#124). In larger specimens, the mastoid process (\#106) is much more pronounced ventrally, the dorsal tip of the crista petrosa (\#118) is more anterodorsal, and the bottom of the fossa subarcuata shows a relatively more posterior position (\#126). 
The premaxillary is slightly more elongated dorsally in larger specimens while the situation is more complex ventrally. Medially, the premaxillary shortens (\#5; \#8) while it elongates laterally (\#7; \#14). The $\mathrm{W}$-shaped process located in the anterior part of the bone (Fig. 1) is more pronounced laterally with a deeper curvature (\#12) and longer processes (\#14). However, the $\mathrm{W}$-shaped process is less sharp medially as its midline point is positioned more posteriorly (\#8). The incisive foramen becomes relatively shorter anteroposteriorly mainly due to the anterior displacement of the most posterior point of these foramina (\#18).

\section{Squamosal (Fig. 5K1-K3)}

The relative allometric reduction of the braincase is also visible on the dorsal edge of the squamosal of larger specimens (\#81; \#83). As for the jugal, we observe a dorsoventral increase of the zygomatic process of the squamosal (\#54; \#56). The posterior root of the zygomatic arch (\#62) is also relatively more posterior. The posterior opening of the posttemporal canal (Gaudin \& Wible, 2006) is more dorsal in larger specimens (\#88). The postglenoid process $(\# 58)$ is more pronounced anterolaterally and the postglenoid foramen (\#60) is positioned slightly more medially. Therefore, the postglenoid process and postglenoid foramen are relatively more distant from one another on larger skulls. The sulcus for the external acoustic meatus (\#64) is shallower and positioned more medially in larger specimens. Finally, the most posteroventral point between the alisphenoid and squamosal (\#72) and the tip of the entoglenoid (\#77) are shifted posteriorly.

\section{Supraoccipital (Fig. 5L1-L3)}

The increase in size is accompanied by a slight lateromedial narrowing (\#83) and a dorsoventral elongation (\#102) of the supraoccipital. The processes of the nuchal crests undergo a strong posteromedial development in larger specimens (\#86). The external occipital 
crest (\#84) is less prominent. In the inner part of the supraoccipital, the lateral occipital vertical ridges (\#116) are more developed in the anterior part of the caudal cerebral fossa.

\section{ALLOMETRY AT DIFFERENT STAGES}

The allometric proportion of shape variation varies between the juvenile, subadult, and adult stages for a given OBU and for the entire skull in the whole sample (Fig. 6A; Table 4; Table S7). For the entire skull, the allometric proportion decreases from juvenile to adult stages. In the $3 \mathrm{~B}$ approach, the stage with the highest allometric proportion of shape variation varies from one OBU to another. The juvenile stage shows the highest allometric proportion for the maxillary, the frontal, the basioccipital-exoccipital complex, and the petrosal (Fig. 6A; Table 4; Table S7). Allometric effects are often not statistically supported in older stages for these OBUs, as exemplified by the bo-eo OBU that only shows a strongly supported allometric effect at the juvenile stage. The allometric proportion of the maxillary shape variation in juveniles is only slightly higher than that retrieved at the subadult stage. The subadult stage shows the highest allometric proportion for the premaxillary, lacrimal, jugal, palatine, parietal, squamosal, and supraoccipital (Fig. 6A; Table 4; Table S7). Allometric effects are statistically supported only at the subadult stage for the lacrimal, jugal, premaxillary, squamosal, and supraoccipital among these OBUs. The allometric proportion of shape variation is generally very low at the adult stage. The frontal, palatine, parietal, as-os-pt-bs OBU, and petrosal all display allometry at this stage (Fig. 6A; Table 4; Table S7). The nasal bone is the only OBU that shows no stage with a supported static allometry. Stages with the highest allometric proportion for a given OBU generally show a higher slope (Table 4). Thus, the subadult stage is usually characterized by the highest slope coefficients for most OBUs.

The comparison of the angles of each regression slope with respect to the horizontal axis shows that several OBU stages may share a common allometry (Fig. S9, Table 4, Table 
S7-8). By cross-checking these results with the statistical support values obtained for the allometric analyses of a given OBU at a given stage (Table 4 and Fig. 6A), we find that only the juvenile and subadult stages of the maxillary (for which the angles are negative) and the juvenile and adult stages of the petrosal show a common allometry in our sample. This analysis also reveals a significantly different allometric effect between the subadult and adult stages of the palatine and parietal. (Fig. S9, Table 4, Table S7-8).

\section{SIZE VARIATION PER OBU AND ALLOMETRY}

The variation in size of an OBU relative to its mean size is different from one OBU to another and among ontogenetic stages (Fig. 6B). At the juvenile stage, the OBUs with the largest size variations from their mean are the maxillary, nasal, lacrimal, jugal, palatine, squamosal, supraoccipital, and bo-eo OBUs. At the subadult level, OBUs with the largest variation in size constitute the anterior part of the snout (i.e., premaxillary, maxillary, and nasal). In the adult stage, the OBUs with the greatest variation in size from their mean correspond to the lacrimal, jugal, and palatine. Finally, over the entire sample and stages, the size variation of an OBU compared to its average size enables us to sort the OBUs into two categories: those with a large size range (i.e., premaxillary, maxillary, nasal, frontal, lacrimal, jugal, and palatine) and those with a small size range (i.e., parietal, squamosal, as-os-pt-bs OBU, supraoccipital, bo-eo OBU, and petrosal) (Fig. 6B). These patterns of size variation do not reflect the allometric proportions per OBU and per stage. However, the two size categories clearly separate an anterior from a posterior block of OBUs, which recall the allometric pattern detected on the entire skull (Fig. 2 and see Discussion).

\section{DISCUSSION}


In mammals with a wide geographical distribution, such as the Pan-American nine-banded armadillos, allometric patterns can vary with geography and across environments (e.g., Meloro et al. 2014; Bubadué et al. 2015; Ferreira-Cardoso et al., 2019). Recent work on nine-

banded armadillos has shown that variation in cranial shape had an important geographic imprint in this widely distributed species (Hautier et al., 2017). In conjunction with evidence from internal anatomy and molecular data, these observations suggested the existence of four morphotypes (Southern, Central, Northern and Guianan) that potentially correspond to different species or subspecies (Huchon et al., 1999; Gibb et al., 2016; Billet et al., 2017; Hautier et al., 2017; Feijó et al., 2018, 2019; Arteaga et al., 2020). Regarding allometry, our results show that the percentage of variation in skull shape due to the interaction between geography and size is weak at the ontogenetic level $\left(R^{2}=3.16 \%\right.$ - Fig. S4) and statistically unsupported at the static level. The slight difference in ontogenetic allometric trajectories among morphotypes of $D$. novemcinctus ssp. must be considered cautiously as it may be due to insufficient juvenile samplings in the Northern morphotype. A weak relationship between geography and allometry was also described in subspecies of the widespread Eurasian red squirrel (Marr \& MacLeod, 2019), for which subtle and continuous mandibular shape changes were retrieved.

Our comparison of allometric patterns between the whole sample and the Southern morphotype in nine banded armadillos further demonstrates that overall cranial allometric patterns are well conserved within this potential species complex. While ecological factors such as diet can influence allometric patterns (Wilson, 2013), the distinction suggested by Smith \& Redford (1990) between Central and South American populations (feeding more on termites and ants) and North American populations (more omnivorous) questions the influence of diet on allometric variation. But, the weak link between geography and allometry 
in nine-banded armadillos also suggests that there is no clear influence of diet on overall cranial allometric patterns either.

\section{MAIN ALLOMETRIC VARIATIONS}

\section{Entire Skull approach}

Allometry was recognized as an important component of mammalian skull variation, often accounting for about a third of the cranial variation at intra- and interspecific levels in mammals (Frost et al., 2003; Hallgrímsson et al., 2009; Cassini, 2013; Hallgrímsson et al., 2015). Nine-banded armadillos are no exception with nearly $28 \%$ of the total cranial shape variation explained by size at the ontogenetic level. The two major ontogenetic allometric trends detected here were the relative snout elongation and the reduction of braincase proportions, which is reminiscent of previous results dealing with mammalian species (Drake \& Klingenberg, 2008; Moyano et al., 2018; Heck et al., 2019). This pattern, often designated as craniofacial allometry, was also detected at the evolutionary level in many groups of mammals (Cardini \& Polly, 2013; Cardini et al., 2015; Tamagnini et al., 2017). Cardini (2019) proposed that craniofacial allometry could represent a much widespread pattern of vertebrate morphological evolution.

In nine-banded armadillos, our analysis highlights some important additional allometric patterns on the entire skull, which could be summarized as follows:

(i) The elongation of the snout is accompanied by a relative dorsoventral flattening and a lateromedial narrowing. At the intraspecific level, previous studies have also characterised a similar narrowing (e.g., Segura \& Prevosti, 2012) or flattening (e.g., Ferreira-Cardoso et al., 2019) of the snout.

(ii) When size increases and the snout elongates, the length of the dental row (excluding the M1; see Material and Methods) shortens relatively to the entire 
skull at both the ontogenetic and static levels (Fig. 2), which might suggest that its size does not increase much during ontogeny. Several species belonging to the genus Dasypus stand out among extant armadillos in showing dental replacement of most of their cheek teeth (Ciancio et al., 2011). Further research is needed to establish whether this allometric reduction of the dental row proportion is specific to nine-banded armadillos or more widespread in other xenarthran species. It is indeed worth noting that this variation is known to be reversed in other mammals such as pronghorns (Moyano et al., 2020), zokors (Kang et al., 2020) or howler monkeys (Meloro et al., 2014) in which the relative length of the upper dental row increases relative to the length of the skull.

(iii) The orbitotemporal region shows a relative widening as the size increases, with a deeper post-orbital constriction, a dorsoventally higher zygomatic arch and a wider temporal fenestra. An allometric relationship between these two parts of the orbitotemporal region has already been described in a canid species (Segura \& Prevosti, 2012) while in horses the opposite variation is observed (Heck et al., 2019). It was noted that the effect of allometry throughout the orbitotemporal region is highly contrasted at the evolutionary level within mammalian groups, which is probably due to the functional relationship between the masticatory muscles and normal oculomotor function (Heesy, 2005).

(iv) Much of the allometric shape changes found at the static level were already detected with clearly higher proportions at the ontogenetic level, except for the parietal and palatine bones (Fig. 7A). The high proportion of static allometry 
600

601

602

603

604

605

606

607

608

609

610

611

612

613

614

615

616

617

618

619

620

621

622

occurs late during ontogeny (Fig. 6A), exhibits high phenotypic plasticity or is subject to high selective pressure (Pélabon et al., 2013). This result is particularly interesting in the case of long-nosed armadillos as their palatal region bears several diagnostic traits for the genus Dasypus (Feijó \& CordeiroEstrela, 2016). It would be worth performing the same analyses in other Dasypus species to see if this allometric pattern is conserved within dasypodines and how it relates to the diagnostic features used to distinguish species (Feijó et al., 2019).

(1)

\section{Bone-By-Bone (3B) approach and the complexity of cranial allometry}

Most studies on cranial allometry involved analyses of covariation between local cranial distances and the skull length (e.g., Goswami \& Prochel, 2007; Wilson, 2011; Wilson, 2013;

Wilson, 2018), or multivariate regressions over a set of cranial landmarks (GMM data) using a whole-skull Procrustes alignment (e.g., Monteiro et al., 1999; Cardini \& O’Higgins, 2005;

Heck et al., 2019; this study). A few studies, however, detailed allometric patterns on specific regions of the skull with the use of linear distances (e.g., Billet et al., 2015). Our 3B analysis may represent a novel approach, to our knowledge, as it uses geometric morphometrics to pinpoint and compare allometric variations at a smaller anatomical scale, such as individual bones, while changing the referential for the Procrustes alignment. Such an approach enabled us to detect previously unnoticed allometric variations and to reveal an untapped complexity of allometric patterns. The scrutiny of different spatial scales has important implications for studies on morphological integration and modularity, because growth patterns and allometry are essential factors for morphological integration (Porto et al., 2013; Klingenberg, 2013; Mitteroecker et al., 2020). Such detailed characterisation of shape variation linked to size 
should also help towards a better knowledge and more appropriate treatment of correlated characters in morphological phylogenetics (Billet \& Bardin, 2019).

The differences in allometric variation found in specific regions of the skull, with the entire skull (ES) and 3B approaches at the ontogenetic and static levels, show that the whole cranial allometric variation results from a complex superimposition of different allometric patterns expressed at different times and locations. At the ontogenetic level, our 3B analyses enabled to highlight major cranial allometric variations for most cranial units (OBUs; see Material \& Methods), which differ from the ones retrieved using the ES. For instance, a sizerelated dorsoventral elongation and mediolateral shortening of the supraoccipital was detected with the 3B approach but not with the ES analyses (Fig. 2, Fig. 5L1-L3). These results partly agree with the bivariate analyses of Goswami \& Prochel (2007), which showed that the width of the supraoccipital followed an isometric growth in the common European mole (Talpa europaea Linnaeus, 1758) while its height displayed positive allometry. Our 3B analyses also highlighted that the processes of the nuchal crests undergo a strong posteromedial development as size increases. Obviously, different allometric patterns could potentially be detected when considering different scales (e.g., focus on the basicranium region instead of a given bone).

\section{HETEROGENEITY OF CRANIAL ALLOMETRY IN SPACE AND TIME}

Our study shows that the degree of allometric shape variation is not homogeneously distributed among the skull bones of nine-banded armadillos. Our 3B analyses most particularly revealed that the allometric proportions of shape variation are regionalised. Cranial units displaying the highest allometric proportions are not necessarily located close to one another (Fig. 3). The relation with cranial size differs between OBUs, which is in line with bivariate analyses demonstrating that most distances measured on mammalian skulls 
follow different allometric trends (e.g., Abdala et al., 2001; Marroig \& Cheverud, 2004; Goswami \& Prochel, 2007; Wilson, 2011; Segura \& Prevosti, 2012; Moyano et al., 2018). This heterogeneity of allometric proportions per cranial unit could not be explained by the variation in size during ontogeny (see Results and Figs. 6A-B, 7A). Similarly, both the prenatal skull ossification sequence (Fig. 7C - see Hautier et al., 2011) and the embryonic origin of each bone (Fig. 7D - see Piekarski et al., 2014) could not explain the differences in allometric proportions observed. Slight methodological artefacts (e.g., number of landmarks per object) and the multiplicity of developmental and genetic processes at stake during local cranial morphogenesis (Hallgrímsson et al., 2019) may explain the heterogeneous pattern found in our study. In addition, the proportion of total shape variation of each cranial unit explained by an independent variable, here size, may also depend on how much other variables (e.g., environment) explain total shape variation and how these overlap with size.

We demonstrated that cranial units located in the anterior half of the skull vary more in size during postnatal development than those in the posterior half (Figs. 6B, 7A - see Segura \& Prevosti, 2012 for another example in Canidae). This result echoes the ontogenetic pattern of allometric variation of the entire skull where a clear separation could be made between the snout and braincase (Fig. 2). In contrast to the mosaic distribution of allometric proportions, such a division of the skull into two parts (or modules) is more congruent with the skull ossification sequence and the embryonic origin of each bone (with the exclusion of the squamosal) (Fig. 7).

Considering several ontogenetic stages contribute to a better understanding of the relative influences of the various developmental periods to the observed allometric patterns (Klingenberg \& Zimmermann, 1992; Mitteroecker et al., 2013). Although preliminary, and pending confirmation for each morphotype, our results show that the allometric proportion of shape variation regularly decreases with age for the entire skull, as well as for most cranial 
units (Fig. 6A), as could be expected for mammals (finite growth). However, the allometric proportions over time differ between cranial units as illustrated by OBUs having higher allometric proportions at the juvenile stage than at other stages (maxillary, frontal, bo-eo OBU and petrosal), and OBUs displaying higher or better supported allometric proportions in subadults and adults than in juveniles (palatine and parietal) (Fig. 6A). We thus characterized a partition across developmental stages in each cranial unit, superimposed to the partition in the allometric proportion of shape variation among cranial bones. This heterogeneity of cranial allometry in time and space in nine-banded armadillos strongly suggests the existence of a complex modular architecture. Such modularity might facilitate the evolvability of the phenotype and be a prerequisite for heterochronic evolutionary changes, which are often local and mosaic (Mitteroecker et al., 2004; Gerber \& Hopkins, 2011).

Several authors (Zumpano \& Richtsmeier 2003; Goswami \& Prochel, 2007; Sardi et al., 2007; Wilson, 2011) have shown that birth may constitute a clear-cut transition in the growth dynamics of several cranial units in rodents and primates, especially for the cranial roof. Since nine-banded armadillos are precocial (Derrickson, 1992; Krmpotic et al., 2012), much of the allometric variation patterns found in our postnatal sample may also be expressed prenatally (Zelditch et al., 2003; Wilson; 2018), a hypothesis that could be tested on a sample including foetuses. These analyses of allometric patterns could also be performed in different armadillo species, at both the intraspecific and interspecific levels, to see how allometric patterns are comparable between species and whether they are maintained at an evolutionary scale (e.g., Gerber et al., 2008; Esquerré et al., 2017; Wilson, 2018).

\section{ACKNOWLEDGMENTS}


We are grateful to Christiane Denys, Violaine Nicolas, and Géraldine Véron, (Muséum National d'Histoire Naturelle, Paris, France), Roberto Portela Miguez, Louise Tomsett, and Laura Balcells (British Museum of Natural History, London, UK), Eileen Westwig (American Museum of Natural History, New York, USA), Nicole Edmison and Chris Helgen (National Museum of Natural History, Washington, DC, USA), Jake Esselstyn (Louisiana State University, Museum of Natural Sciences, Baton Rouge, USA), Manuel Ruedi (Muséum d'Histoire Naturelle, Geneva, Switzerland) for access to comparative material. We thank Benoit de Thoisy (Institut Pasteur de la Guyane) and Clara Belfiore for their help with the data acquisition, Cyril Le Verger for his help in the 3D isolation of cranial units, Rémi Lefebvre (Muséum National d'Histoire Naturelle) for his help on the definition of internal landmarks, Sérgio Ferreira-Cardoso (Institut des Sciences de l'Evolution) and Olivia Plateau (University of Fribourg, Switzerland) for interesting discussions on covariation patterns, and Christian de Muizon (Muséum National d'Histoire Naturelle) for anatomical discussions. Renaud Lebrun (Institut des Sciences de l'Evolution), Farah Ahmed (British Museum of Natural History), Miguel García-Sanz and Florent Goussard (Platform AST-RX - Muséum National d'Histoire Naturelle) generously provided help and advice on the acquisition of CT scans. Finally, we thank Nilton Cáceres (Federal University of Santa Maria, Brazil) and an anonymous reviewer, for their helpful comments. Some of the experiments were performed using the $\mu-\mathrm{CT}$ facilities of the Montpellier Rio Imaging (MRI) platform of the LabEx CeMEB. This work has benefited from an "Investissements d'Avenir" grant managed by Agence Nationale de la Recherche, France (CEBA, ref. ANR-10-LABX-25-01). This research received support from the Synthesys Project (http://synthesys3.myspecies.info/), which is funded by the European Community Research Infrastructure Action under the FP7. This is contribution ISEM 2020-XXX of the Institut des Sciences de l'Evolution de Montpellier. 
Abba AM, Cassini GH, Valverde G, Tilak MK, Vizcaíno SF, Superina M, Delsuc F. 2015.

725

Systematics of hairy armadillos and the taxonomic status of the Andean hairy armadillo (Chaetophractus nationi). Journal of Mammalogy 96: 673-689.

Abdala F, Flores DA, Giannini NP. 2001. Postweaning ontogeny of the skull of Didelphis albiventris. Journal of Mammalogy 82: 190-200.

Adams DC, Rohlf FJ, Slice DE. 2013. A field comes of age: geometric morphometrics in the 21st century. Hystrix, the Italian Journal of Mammalogy 24: 7-14.

Adams DC, Collyer ML, Kaliontzopoulou A. 2018. Geomorph: Software for geometric morphometric analyses. R package version 3.0.7. R Foundation for Statistical Computing, Vienna, Austria.

Adams DC, Collyer ML, Kaliontzopoulou A. 2019. Geomorph: Software for geometric morphometric analyses. R package version 3.1.1. R Foundation for Statistical Computing, Vienna, Austria.

Anderson MJ. 2001. A new method for non-parametric multivariate analysis of variance. Austral ecology 26: 32-46.

Arteaga MC, Gasca-Pineda J, Bello-Bedoy R, Eguiarte LE, Medellin RA. 2020. Conservation Genetics, Demographic History, and Climatic Distribution of the Nine-Banded Armadillo 
750

(Dasypus novemcinctus): An Analysis of Its Mitochondrial Lineages. In: Ortega J, Maldonado JE, eds. Conservation Genetics in Mammals: Integrative Research Using Novel Approaches. Switzerland: Springer-Cham, 141-163.

Baker J, Meade A, Pagel M, Venditti C. 2015. Adaptive evolution toward larger size in mammals. Proceedings of the National Academy of Sciences 112: 5093-5098.

Billet G, Hautier L, De Muizon C, Valentin X. 2011. Oldest cingulate skulls provide congruence between morphological and molecular scenarios of armadillo evolution. Proceedings of the Royal Society B: Biological Sciences 278: 2791-2797.

Billet G, De Muizon C, Schellhorn R, Ruf I, Ladevèze S, Bergqvist L. 2015. Petrosal and inner ear anatomy and allometry amongst specimens referred to Litopterna (Placentalia). Zoological Journal of the Linnean Society 173: 956-987.

Billet G, Hautier L, De Thoisy B, Delsuc F. 2017. The hidden anatomy of paranasal sinuses reveals biogeographically distinct morphotypes in the nine-banded armadillo (Dasypus novemcinctus). PeerJ 5: e3593.

Billet G, Bardin J. 2019. Serial Homology and Correlated Characters in Morphological Phylogenetics: Modeling the Evolution of Dental Crests in Placentals. Systematic Biology 68: $267-280$. 
777

778

Bokma F, Godinot M, Maridet O, Ladevèze S, Costeur L, Solé F, Gheerbrant E, Peigné S, Jacques F, Laurin M. 2016. Testing for Depéret's rule (body size increase) in mammals using combined extinct and extant data. Systematic biology 65: 98-108.

Bubadué JM, Cáceres N, Carvalho RS, Meloro C. 2015. Ecogeographical variation in skull shape of South-American canids: abiotic or biotic processes? Evolutionary Biology 43: $145 \mathrm{e} 159$.

Cardini A. 2019. Craniofacial allometry is a rule in evolutionary radiations of placentals. Evolutionary Biology 46: 239-248.

Cardini A, O'Higgins P. 2005. Post-natal ontogeny of the mandible and ventral cranium in Marmota species (Rodentia, Sciuridae): allometry and phylogeny. Zoomorphology 124: 189203.

Cardini A, Polly PD. 2013. Larger mammals have longer faces because of size-related constraints on skull form. Nature communications 4: 2458.

Cardini A, Polly D, Dawson R, Milne N. 2015. Why the long face? Kangaroos and wallabies follow the same 'rule' of cranial evolutionary allometry (CREA) as placentals. Evolutionary Biology 42: 169-176.

Cassini GH. 2013. Skull geometric morphometrics and paleoecology of Santacrucian (Late Early Miocene; Patagonia) native ungulates (Astrapotheria, Litopterna, and Notoungulata). Ameghiniana 50: 193-216. 
Ciancio MR, Castro MC, Galliari FC, Carlini AA, Asher RJ. 2011. Evolutionary implications

797

798

799

800

801

802

803

804

805

806

807

808

809

810

811

812

813

814

815

816

817

818

819

of dental eruption in Dasypus (Xenarthra). Journal of Mammalian Evolution 19: 1-8.

Costa FR, Clerici GP, Lobo-Ribeiro L, Rosa PS, Rocha-Barbosa O. 2019. Analysis of the spatio-temporal parameters of gaits in Dasypus novemcinctus (Xenarthra: Dasypodidae). Acta Zoologica 100: 61-68.

Collyer ML, Adams DC. 2013. Phenotypic trajectory analysis: comparison of shape change patterns in evolution and ecology. Hystrix, the Italian Journal of Mammalogy 24: 75.

Collyer ML, Sekora DJ, Adams DC. 2015. A method for analysis of phenotypic change for phenotypes described by high-dimensional data. Heredity 115: 357.

Delsuc F, Gibb GC, Kuch M, Billet G, Hautier L, Southon J, Rouillard JM, Fernicola JC, Vizcaíno SF, MacPhee RDE, Poinar HN. 2016. The phylogenetic affinities of the extinct glyptodonts. Current Biology 26: R155-R156.

Derrickson EM. 1992. Comparative reproductive strategies of altricial and precocial eutherian mammals. Functional Ecology: 57-65.

Drake AG, Klingenberg CP. 2008. The pace of morphological change: historical transformation of skull shape in St Bernard dogs. Proceedings of the Royal Society B:

Biological Sciences 275: 71-76. 
Dushoff J, Kain MP, Bolker BM. 2019. I can see clearly now: reinterpreting statistical significance. Methods in Ecology and Evolution 10: 756-759.

Esquerré D, Sherratt E, Keogh JS. 2017. Evolution of extreme ontogenetic allometric diversity and heterochrony in pythons, a clade of giant and dwarf snakes. Evolution 71: 28292844.

Feijó A, Cordeiro-Estrela P. 2016. Taxonomic revision of the Dasypus kappleri complex, with revalidations of Dasypus pastasae (Thomas, 1901) and Dasypus beniensis Lönnberg, 1942 (Cingulata, Dasypodidae). Zootaxa 4170: 271-297.

Feijó A, Patterson BD, Cordeiro-Estrela P. 2018. Taxonomic revision of the long-nosed armadillos, Genus Dasypus Linnaeus, 1758 (Mammalia, Cingulata). PloS one 13: e0195084.

Feijó A, Vilela JF, Cheng J, Schetino MAA, Coimbra RTF, Bonvicino CR, Santos FR, Patterson BD, Cordeiro-Estrela P. 2019. Phylogeny and molecular species delimitation of long-nosed armadillos (Dasypus: Cingulata) supports morphology-based taxonomy. Zoological Journal of the Linnean Society 186: 813-825.

Ferreira-Cardoso S, Billet G, Gaubert P, Delsuc F, Hautier L. 2019. Skull shape variation in extant pangolins (Pholidota: Manidae): allometric patterns and systematic implications. Zoological Journal of the Linnean Society 188: 255-275.

Frappell PB, Boggs DF, Kilgore Jr DL. 1998. How stiff is the armadillo?: A comparison with the allometrics of mammalian respiratory mechanics. Respiration physiology 113: 111-122. 
846 Frost SR, Marcus LF, Bookstein FL, Reddy DP, Delson E. 2003. Cranial allometry,

847 phylogeography, and systematics of large-bodied papionins (primates: Cercopithecinae)

848 inferred from geometric morphometric analysis of landmark data. The Anatomical Record

849 Part A: Discoveries in Molecular, Cellular, and Evolutionary Biology: An Official

850 Publication of the American Association of Anatomists 275: 1048-1072.

851

852 Gaudin T, Wible JR. 2006. The phylogeny of living and extinct armadillos (Mammalia,

853 Xenarthra, Cingulata): a craniodental analysis. In: Carrano MT, Gaudin TJ, Blob RW, Wible

854 JR, eds. Amniote Paleobiology: Perspectives on the Evolution of Mammals, Birds, and

855 Reptiles. Chicago: University of Chicago Press, 153-198.

856

857 Gerber S, Eble GJ, Neige P. 2008. Allometric space and allometric disparity: a developmental

858 perspective in the macroevolutionary analysis of morphological disparity. Evolution:

859 International Journal of Organic Evolution 62: 1450-1457.

860

861

Gerber S, Hopkins MJ. 2011. Mosaic heterochrony and evolutionary modularity: the trilobite

862 genus Zacanthopsis as a case study. Evolution: International Journal of Organic Evolution

863 65: $3241-3252$.

864

865 Gibb GC, Condamine FL, Kuch M, Enk J, Moraes-Barros N, Superina M, Poinar HN, Delsuc 866 F. 2016. Shotgun mitogenomics provides a reference phylogenetic framework and timescale 867 for living xenarthrans. Molecular Biology and Evolution 33: 621-642.

868 
Good PI. 2000. Permutation tests: a practical guide to resampling methods for testing hypotheses. Berlin: Springer-Verlag, 2nd eds.

Goodall C. 1991. Procrustes methods in the statistical analysis of shape. Journal of the Royal Statistical Society: Series B (Methodological) 53: 285-321.

Goswami A, Prochel J. 2007. Ontogenetic morphology and allometry of the cranium in the common European mole (Talpa europaea). Journal of Mammalogy 88: 667-677.

Goswami A, Finarelli JA. 2016. EMMLi: a maximum likelihood approach to the analysis of modularity. Evolution 70: 1622-1637.

Hallgrímsson B, Jamniczky H, Young NM, Rolian C, Parsons TE, Boughner JC, Marcucio RS. 2009. Deciphering the palimpsest: studying the relationship between morphological integration and phenotypic covariation. Evolutionary biology 36: 355-376.

Hallgrímsson B, Percival CJ, Green R, Young NM, Mio W, Marcucio R. 2015.

Morphometrics, 3D imaging, and craniofacial development. In Current topics in developmental biology 115: 561-597.

Hallgrímsson B, Katz DC, Aponte JD, Larson JR, Devine J, Gonzalez PN, Young NM, Roseman CC, Marcucio RS. 2019. Integration and the Developmental Genetics of Allometry. Integrative and comparative biology 59: 1369-1381. 
901

906

907

908

909

910

911

Hautier L, Weisbecker V, Goswami A, Knight F, Kardjilov N, Asher RJ. 2011. Skeletal ossification and sequence heterochrony in xenarthran evolution. Evolution \& development 13: $460-476$.

Hautier L, Billet G, De Thoisy B, Delsuc F. 2017. Beyond the carapace: skull shape variation and morphological systematics of long-nosed armadillos (genus Dasypus). PeerJ 5: e3650.

Heck L, Sánchez-Villagra MR, Stange M. 2019. Why the long face? Comparative shape analysis of miniature, pony, and other horse skulls reveals changes in ontogenetic growth. PeerJ 7: e7678.

Heesy CP. 2005. Function of the mammalian postorbital bar. Journal of Morphology 264: $363-380$.

Hoffman EA, Rowe TB. 2018. Jurassic stem-mammal perinates and the origin of mammalian reproduction and growth. Nature 561: 104.

\section{Huchon D, Delsuc F, Catzeflis FM, Douzery EJ. 1999. Armadillos exhibit less genetic} polymorphism in North America than in South America: nuclear and mitochondrial data confirm a founder effect in Dasypus novemcinctus (Xenarthra). Molecular Ecology 8: 17431748.

Izenman AJ. 2013. Multivariate regression. In: Izenman AJ, ed. Modern Multivariate Statistical Techniques. New York: Springer-Verlag, 159-194. 
Kang Y, Su J, Yao B, Ji W, Hegab IM, Hanafy AM, Zhang D. 2020. Geometric

morphometric analysis of the plateau zokor (Eospalax baileyi) revealed significant effects of environmental factors on skull variations. Zoology: 125779.

Klingenberg CP. 2013. Cranial integration and modularity: insights into evolution and development from morphometric data. Hystrix, the Italian Journal of Mammalogy 24: 43-58.

Klingenberg CP. 2016. Size, shape, and form: concepts of allometry in geometric morphometrics. Development genes and evolution 226: 113-137.

Klingenberg CP, Zimmermann M. 1992. Static, ontogenetic, and evolutionary allometry: a multivariate comparison in nine species of water striders. The American Naturalist 140: 601620.

Klingenberg CP, McIntyre GS. 1998. Geometric morphometrics of developmental instability: analyzing patterns of fluctuating asymmetry with Procrustes methods. Evolution 52: 13631375.

Klingenberg CP, Barluenga M, Meyer A. 2002. Shape analysis of symmetric structures: quantifying variation among individuals and asymmetry. Evolution 56: 1909-1920.

Krmpotic CM, Galliari FC, Barbeito CG, Carlini AA. 2012. Development of the integument of Dasypus hybridus and Chaetophractus vellerosus, and asynchronous events with respect to the postcranium. Mammalian Biology - Zeitschrift für Säugetierkunde 77: 314-326. 
Linde-Medina M. 2016. Testing the cranial evolutionary allometric 'rule' in Galliformes.

Journal of evolutionary biology 29: 1873-1878.

945

Linnaeus C. 1758. Systema naturae per regna tria naturce, secundum classes, ordines, genera,

947

949

950

951

952

953

954

955

956

957

958

959

960

961

962

963

964

965

species, cum characteribus, differentiis, synonymis, locis. Tomus I. Editio decima, reformata.

Homiae: Laurentii Salvii.

Marr MM, MacLeod N. 2019. Geographical variation in Eurasian red squirrel (Sciurus vulgaris L., 1758) mandibles and the issue of subspecies-level organization: a failure of history? Biological Journal of the Linnean Society 128: 337-359.

Marroig G, Cheverud JM. 2004. Cranial evolution in sakis (Pithecia, Platyrrhini) I: interspecific differentiation and allometric patterns. American Journal of Physical Anthropology: The Official Publication of the American Association of Physical Anthropologists 125: 266-278.

Meloro C, Cáceres N, Carotenuto F, Passaro F, Sponchiado J, Melo GL, Raia P. 2014.

Ecogeographical variation in skull morphometry of howler monkeys (Primates: Atelidae).

Zoologischer Anzeiger 253: 345e359.

Mitteroecker P, Gunz P, Weber GW, Bookstein FL. 2004. Regional dissociated heterochrony in multivariate analysis. Annals of Anatomy - Anatomischer Anzeiger 186: 463-470. 
969

970

971

972

973

974

975

976

977

978

979

980

981

982

983

984

985

986

987

988

989

Mitteroecker P, Gunz, P, Windhager S, Schaefer K. 2013. A brief review of shape, form, and allometry in geometric morphometrics, with applications to human facial morphology. Hystrix 24: 59-66.

Mitteroecker P, Bartsch S, Erkinger C, Grunstra NDS, Le Maître A, Bookstein FL. 2020.

Morphometric Variation at Different Spatial Scales: Coordination and Compensation in the

Emergence of Organismal Form. Systematic Biology: syaa007

Moeller W. 1968. Allometrische analyse der gürteltierschädel. Ein beitrag zur phylogenie der Dasypodidae Bonaparte, 1838. Zoologische Jahrbücher. Abteilung für Anatomie und Ontogenie der Tiere 85: 411-528.

Monteiro LR, Less LG, Abe AS. 1999. Ontogenetic variation in skull shape of Thrichomys apereoides (Rodentia: Echimyidae). Journal of Mammalogy 80: 102-111.

Moyano SR, Cassini GH, Giannini NP. 2018. Skull Ontogeny of the Hyraxes Procavia capensis and Dendrohyrax arboreus (Procaviidae: Hyracoidea). Journal of Mammalian Evolution 26: 317-331.

Moyano SR, Morales MM, Giannini NP. 2020. Skull ontogeny of the pronghorn (Antilocapra americana) in the comparative context of native North American ungulates. Canadian Journal of Zoology 98: 165-174.

Nummela S. 1995. Scaling of the mammalian middle ear. Hearing research 85: 18-30. 
994

Pélabon C, Bolstad GH, Egset CK, Cheverud JM, Pavlicev M, Rosenqvist G. 2013. On the relationship between ontogenetic and static allometry. The American Naturalist 181: 195212.

Piekarski N, Gross JB, Hanken J. 2014. Evolutionary innovation and conservation in the embryonic derivation of the vertebrate skul. Nature Communications 5: 5661.

Porto A, Shirai LT, de Oliveira FB, Marroig G. 2013. Size variation, growth strategies, and the evolution of modularity in the mammalian skull. Evolution 67: 3305-3322.

Price SA, Hopkins SS. 2015. The macroevolutionary relationship between diet and body mass across mammals. Biological Journal of the Linnean Society 115: 173-184.

Rohlf FJ, Slice D. 1990. Extensions of the Procrustes method for the optimal superimposition of landmarks. Systematic Biology 39: 40-59.

Ross CF, Metzger KA. 2004. Bone strain gradients and optimization in vertebrate skulls. Annals of Anatomy-Anatomischer Anzeiger 186: 387-396.

Sánchez-Villagra MR. 2012. Embryos in deep time: the rock record of biological development. San Francisco: University of California Press.

Sardi ML, Ventrice F, Rozzi FR. 2007. Allometries throughout the late prenatal and early postnatal human craniofacial ontogeny. The Anatomical Record: Advances in Integrative Anatomy and Evolutionary Biology 290: 1112-1120. 
Schlager S. 2017. Morpho and Rvcg - Shape Analysis in R: R-Packages for Geometric

1018

1019

1020

1021

1022

1023

1024

1025

1026

1027

1028

1029

1030

1031

1032

1033

1034

1035

1036

1037

1038

1039

Morphometrics, Shape Analysis and Surface Manipulations. In: Zheng G, Li S, Szekely G, eds. Statistical Shape and Deformation Analysis. London: Academic Press, 217-256.

Schneider CA, Rasband WS, Eliceiri KW. 2012. NIH Image to ImageJ: 25 years of image analysis. Nature methods 9: 671.

Segura V, Prevosti F. 2012. A quantitative approach to the cranial ontogeny of Lycalopex culpaeus (Carnivora: Canidae). Zoomorphology 131: 79-92.

Sibly RM, Brown JH. 2007. Effects of body size and lifestyle on evolution of mammal life histories. Proceedings of the National Academy of Sciences 104: 17707-17712.

Slater GJ, Van Valkenburgh B. 2009. Allometry and performance: the evolution of skull form and function in felids. Journal of evolutionary biology 22: 2278-2287.

Slijper EJ. 1962. Whales. London: Hutchinson and Co.

Smith K, Redford KH. 1990. The anatomy and function of the feeding apparatus in two armadillos (Dasypoda): anatomy is not destiny. Journal of Zoology 222: 27-47.

Smith FA, Boyer AG, Brown JH, Costa DP, Dayan T, Ernest SKM, Evans AR, Fortelius M, Gittleman JL, Hamilton MJ, Harding LE, Lintulaakso K, Lyons SK, McCain C, Okie1 JG, 
Saarinen JJ, Sibly RM, Stephens PR, Theodor J, Uhen MD. 2010. The evolution of maximum body size of terrestrial mammals. Science 330: 1216-1219.

Superina M, Abba AM. 2018. Family Chlamyphoridae (Chlamyphorid armadillos). Handbook of the mammals of the world 8: 48-73.

Tamagnini D, Meloro C, Cardini A. 2017. Anyone with a long-face? Craniofacial

Evolutionary Allometry (CREA) in a family of short-faced mammals, the Felidae.

Evolutionary Biology 44: 476-495.

Vizcaíno SF, Milne N. 2002. Structure and function in armadillo limbs (Mammalia:

Xenarthra: Dasypodidae). Journal of Zoology 257: 117-127.

\section{Vizcaíno SF, Cassini GH, Toledo N, Bargo MS. 2012. On the evolution of large size in} mammalian herbivores of Cenozoic. In: Patterson BP, Costa LP, eds. Bones, Clones and Biomes: an 80-million year History of Recent Neotropical Mammals. Chicago and London: The University of Chicago Press, 76-101.

Wetzel RM, Mondolfi E. 1979. The subgenera and species of long-nosed armadillos, genus Dasypus L. In: Eisenberg JF, ed. Vertebrate ecology in the northern Neotropics. Washington: Smithsonian Institution Press, 43-63.

Wilson LA. 2011. Comparison of prenatal and postnatal ontogeny: cranial allometry in the African striped mouse (Rhabdomys pumilio). Journal of Mammalogy 92: 407-420. 
1065 Wilson LA. 2013. Allometric disparity in rodent evolution. Ecology and evolution 3: 9711066984.

1067

1068 Wilson LA. 2018. The evolution of ontogenetic allometric trajectories in mammalian 1069 domestication. Evolution 72: 867-877.

1070

1071 Zelditch ML, Sheets HD, Fink WL. 2003. The ontogenetic dynamics of shape disparity. 1072 Paleobiology 29: 139-156.

1073

1074

1075

Zumpano MP, Richtsmeier JT. 2003. Growth-related shape changes in the fetal craniofacial complex of humans (Homo sapiens) and pigtailed macaques (Macaca nemestrina): a 3D-CT

1076 comparative analysis. American Journal of Physical Anthropology 120: 339-351.

1077

1078

1079

1080

1081

1082

1083

1084

1085

1086

1087

1088

1089 


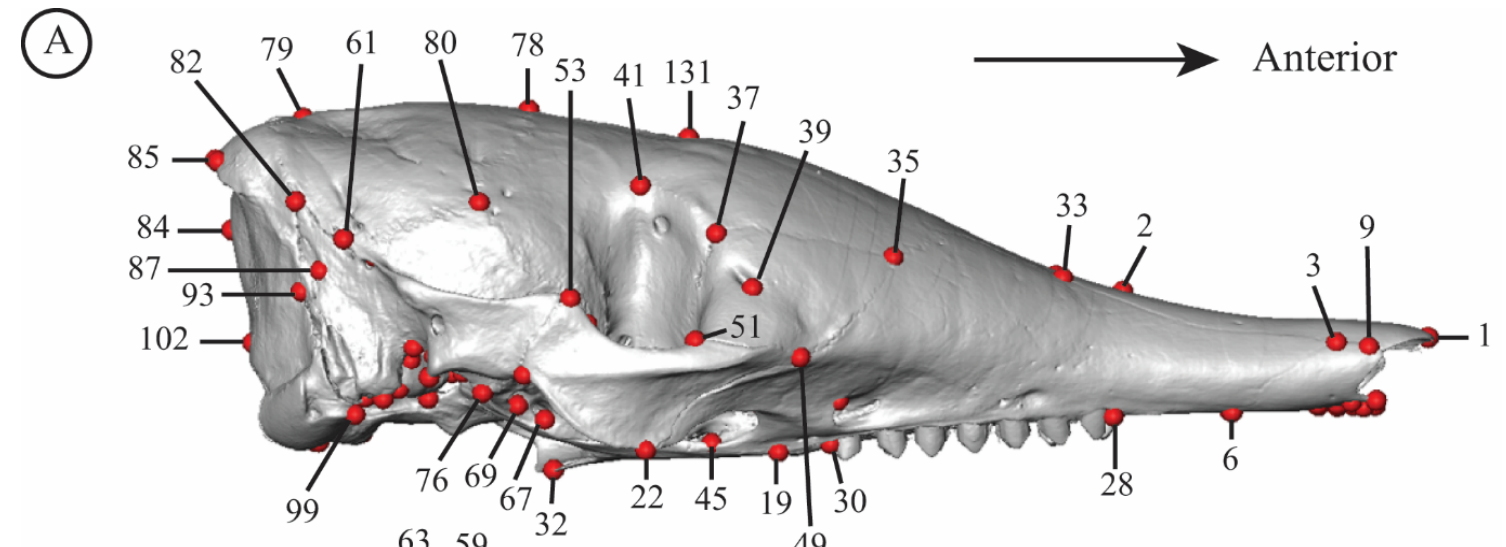

(B)

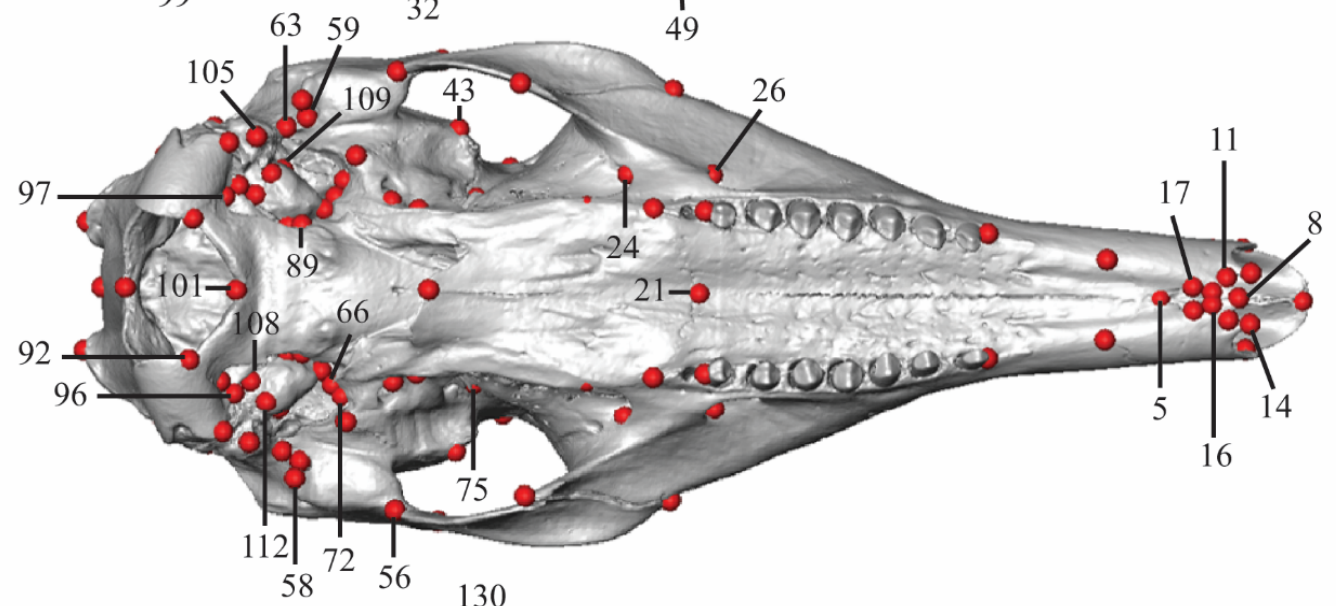

(C)

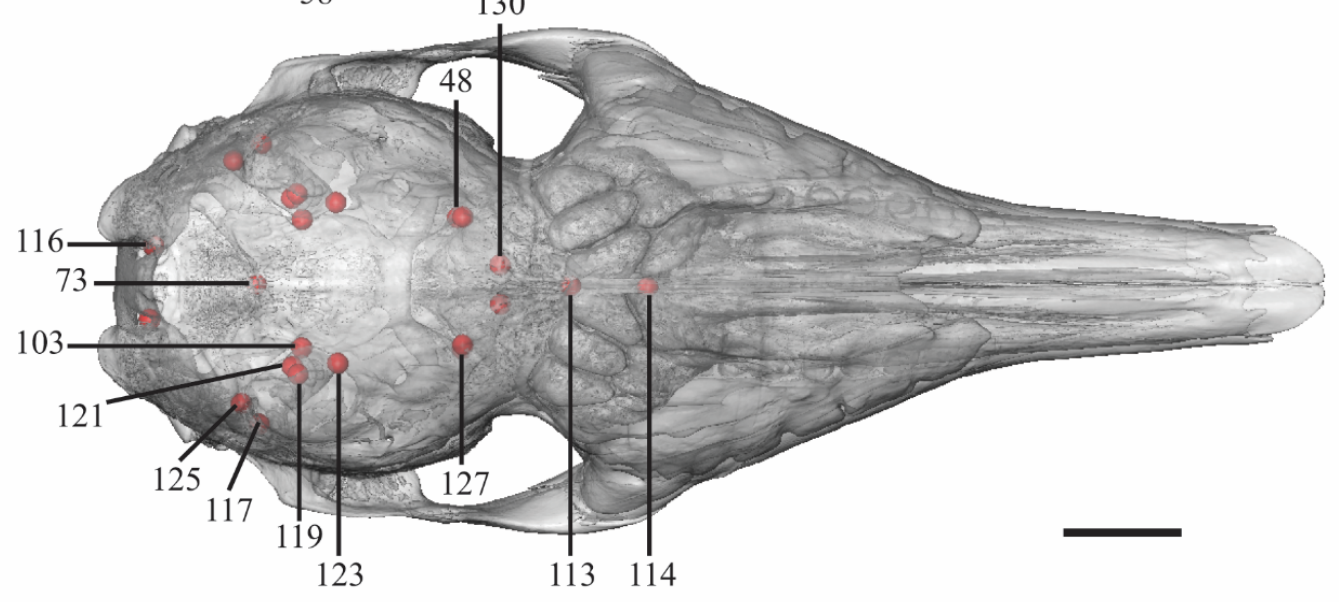

Figure 1. Landmarks digitized on the skull of Dasypus novemcinctus (MNHN.CG.2006-565). Lateral (A), ventral (B), and dorsal (C) views. The skull in dorsal view is shown with bone transparency $(25 \%)$. Scale-bar $=1 \mathrm{~cm}$. List of landmarks can be found in Table 1 and Table 2. 

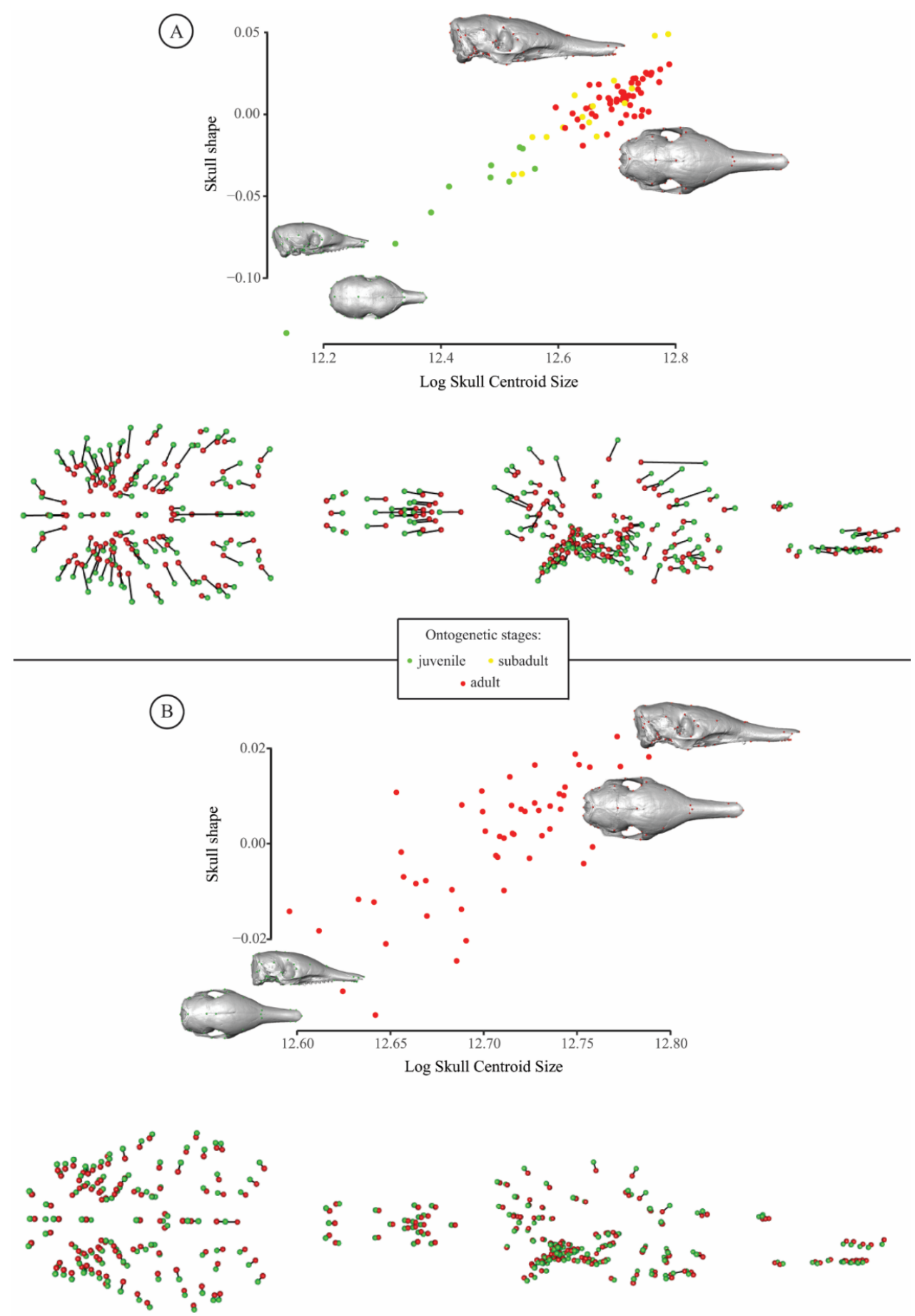

Figure 2. Ontogenetic and static allometry on the entire skull (ES) of nine-banded armadillos. Ontogenetic stages are represented with different colours (juvenile $=$ green; subadult $=$ yellow; adult = red; see text for more detail). For graphical display, we used the projected regression scores of the shape data to represent shape variation related to changes in $\log$ centroid size (Adams et al., 2013). Shape changes were visualized as vectors from the minimal shape (green) to the maximal shape (red) of the shape regression scores corresponding to the projection of the data points in shape space on to an axis in the direction of the regression vector (see Drake \& Klingenberg, 2008). A. Multivariate regression of skull shape on log skull centroid size at the ontogenetic level, representing $27.62 \%$ of the total shape variation. B. Same analysis, at the static level $(6.31 \%$ of total shape variation) (see text). 

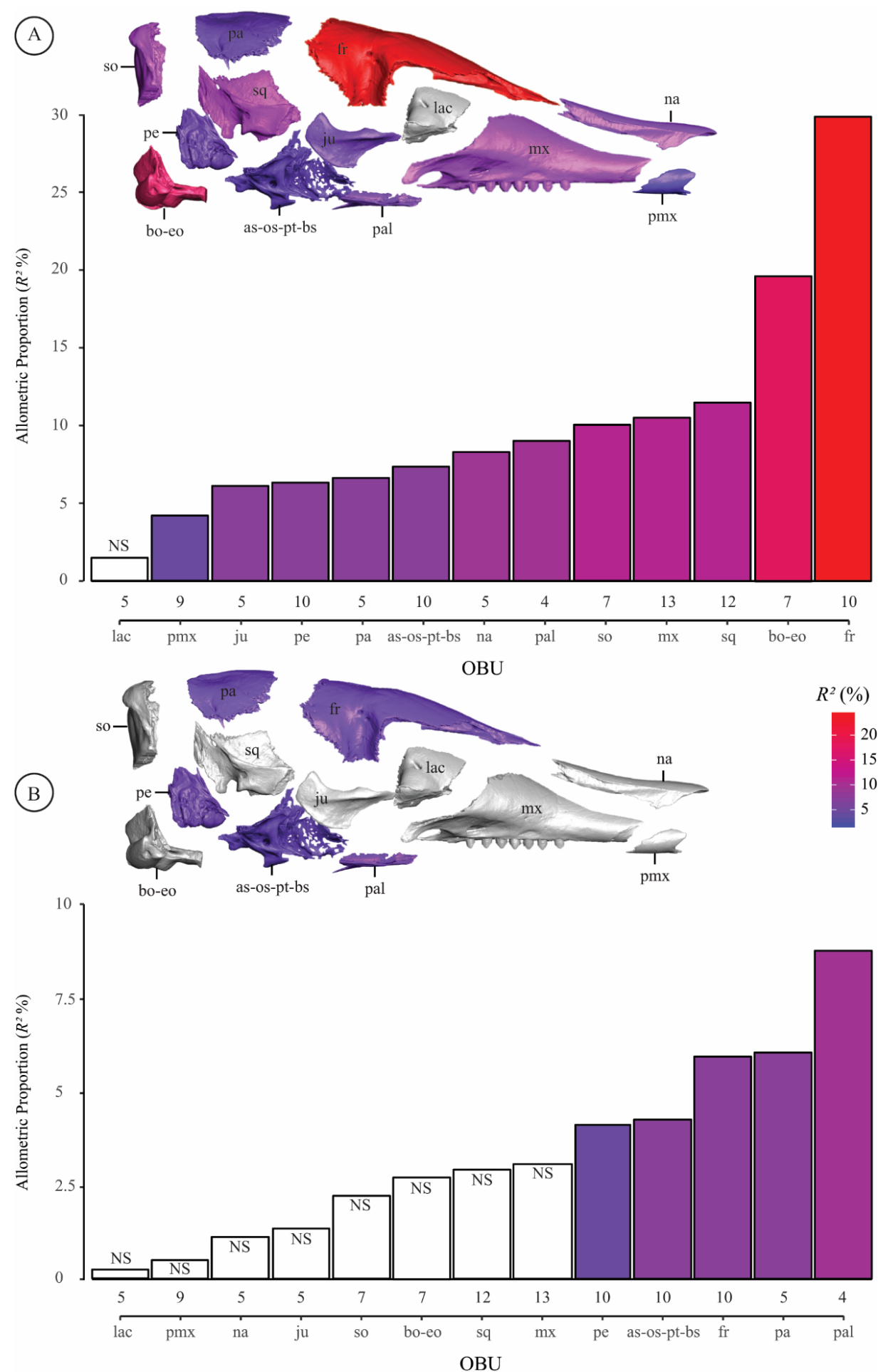

1109 Figure 3. Bar graphs showing the allometric proportions $\left(R^{2}\right)$ of each cranial unit's (OBU) total shape variation under the $3 \mathrm{~B}$ approach (see text), at the ontogenetic (A) and static (B) levels. Allometric proportions are shown with the log skull centroid size taken as size variable. On the virtually dislocated skull (in right lateral view), the allometric proportions are reported in corresponding colours. White bars indicate a statistically unsupported (NS) allometry for a given OBU (at $p$ value $>0.05$ ). Abbreviations of OBUs: as-os-pt-bs, alisphenoid-orbitosphenoid-pterygoid-basisphenoid complex; bo-eo, basioccipital-exoccipital complex; fr, frontal; ju, jugal; lac, lacrimal; mx, maxillary; na, nasal; pa, parietal; pal, palatine; pe, petrosal; pmx, premaxillary; so, supraoccipital; sq, squamosal. 

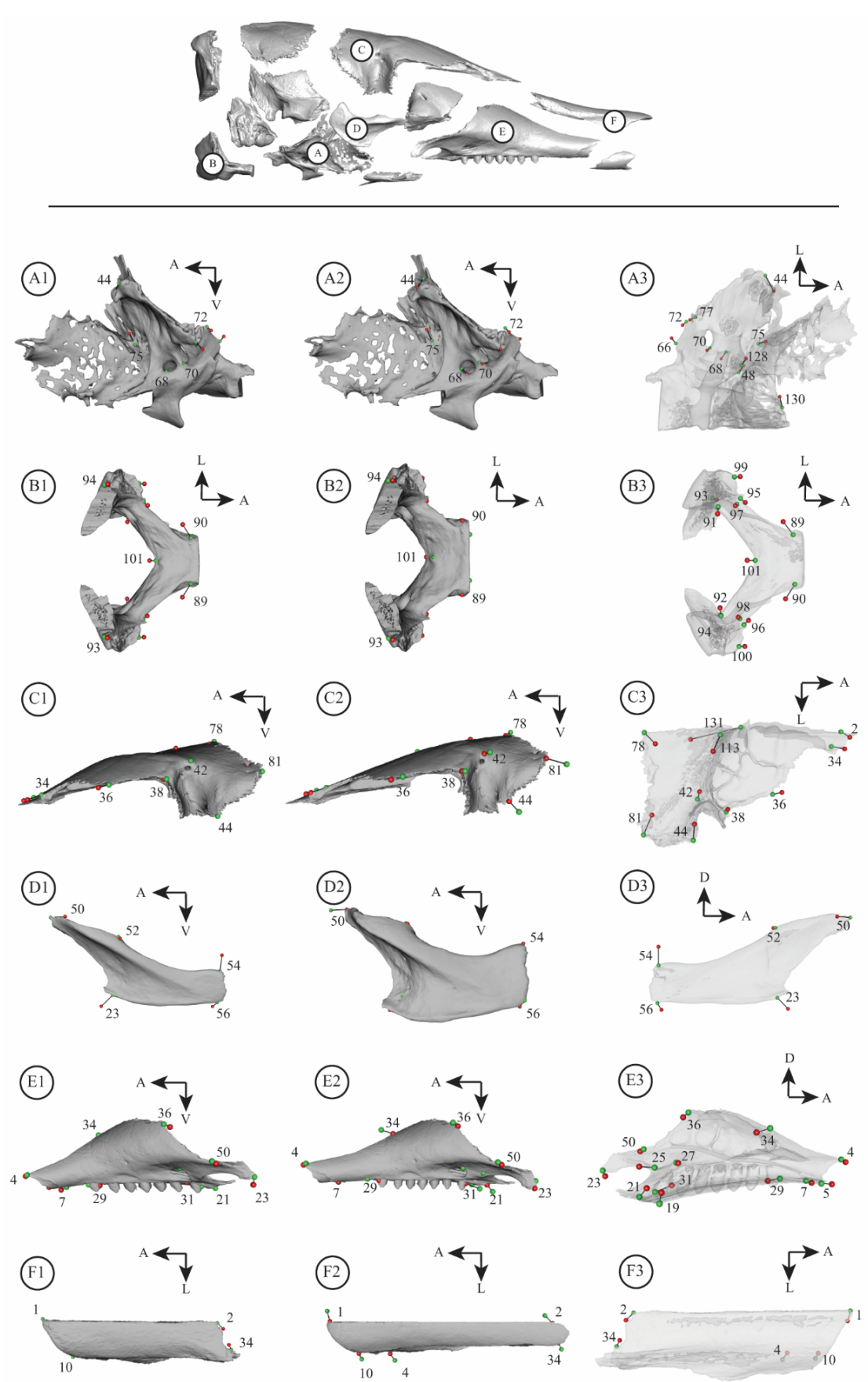

1119 Figure 4. Vector representation of the allometric shape changes detected for a given cranial unit (OBU), represented between its minimal (green - smaller centroid size) and maximal (red - larger centroid size) shape (see Fig. 2). Results of the analysis performed at the ontogenetic level, and with the log skull centroid size taken as the size variable (see text). For each OBU, the changes are shown in three subsections organized horizontally: 1, vectors from minimal to maximal shape with minimal OBU shape; 2 , same as 1 ) with maximal OBU shape; 3 , minimal OBU shape in transparency with vectors. A) alisphenoid-orbitosphenoid-pterygoidbasisphenoid complex; A1-A2, lateral view; A3, dorsal view. B) basioccipital-exoccipital complex; B1-B2, dorsal view; B3, ventral view. C) frontal; $\mathrm{C} 1-\mathrm{C} 2$, lateral view; C3, ventral view. D) jugal; D1-D2, lateral view; D3, medial view. E) maxillary; E1-E2, lateral view; E3, medial view. F) nasal; F1-2, dorsal view; F3, ventral view. Landmark numbers and orientation arrows were added for more readability as well as the overall representation of the unpaired bone (basioccipital). Abbreviations: A, anterior; D, dorsal; L, lateral; V, ventral. 
(G1)

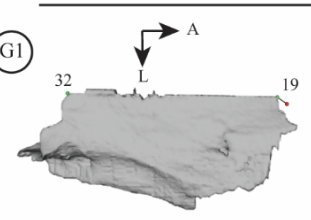

(H1)

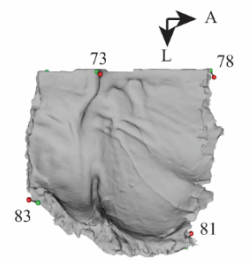

(11)

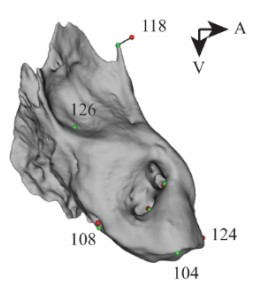

(11)

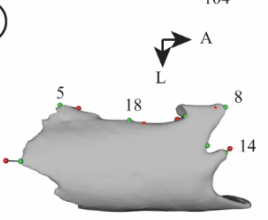

(K1)

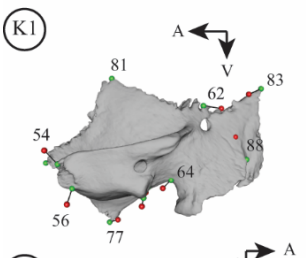

(L1)

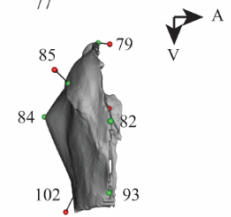

(12)

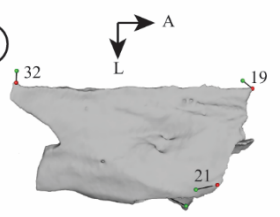

(12)

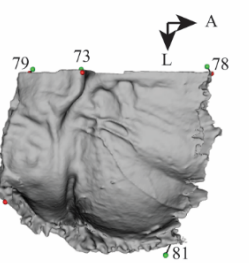

(12)

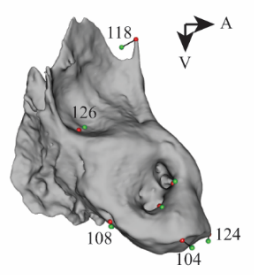

(12)

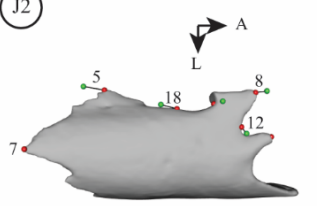

(스)

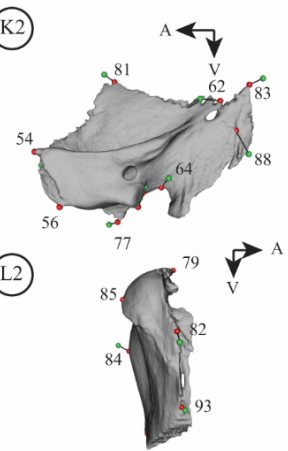

(G3) $\stackrel{\mathrm{L}}{\hookrightarrow}$

(H3)

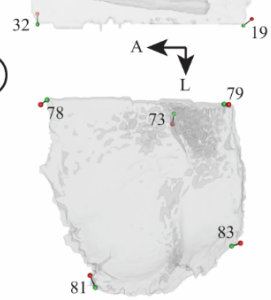

(13)

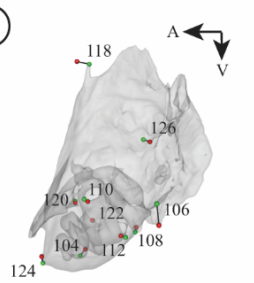

(J3)

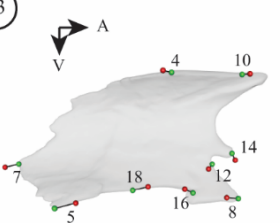

(K3)
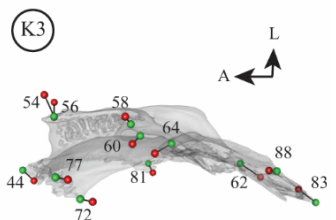

(L3)

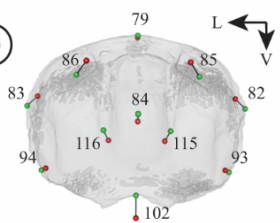

Figure 5. Vector representation of the allometric shape changes detected for a given cranial unit (OBU), represented between its minimal (green - smaller centroid size) and maximal (red - larger centroid size) shapes (see Fig. 2). Results of the analysis performed at the ontogenetic level, and with the log skull centroid size taken as the size variable (see text). For each OBU, the changes are shown in three subsections organized horizontally: 1, vectors from minimal to maximal shape with minimal OBU shape; 2, same as 1) with maximal OBU shape; 3, minimal OBU shape in transparency with vectors. G) palatine; G1-G2, ventral view; G3, dorsal view. H) parietal; H1-H2, ventral view; H3, dorsal view. I) petrosal; I1-I2, medial view; I3, lateral view. J) premaxillary; J1-J2, ventral view; J3, medial view. K) squamosal; K1-K2, lateral view; K3, ventral view. L) supraoccipital; L1-L2, lateral view; L3, occipital view. Landmark numbers and orientation arrows were added for more readability as well as the overall representation of the unpaired bone (supraoccipital). Abbreviations: A, anterior; L, lateral; V, ventral. 


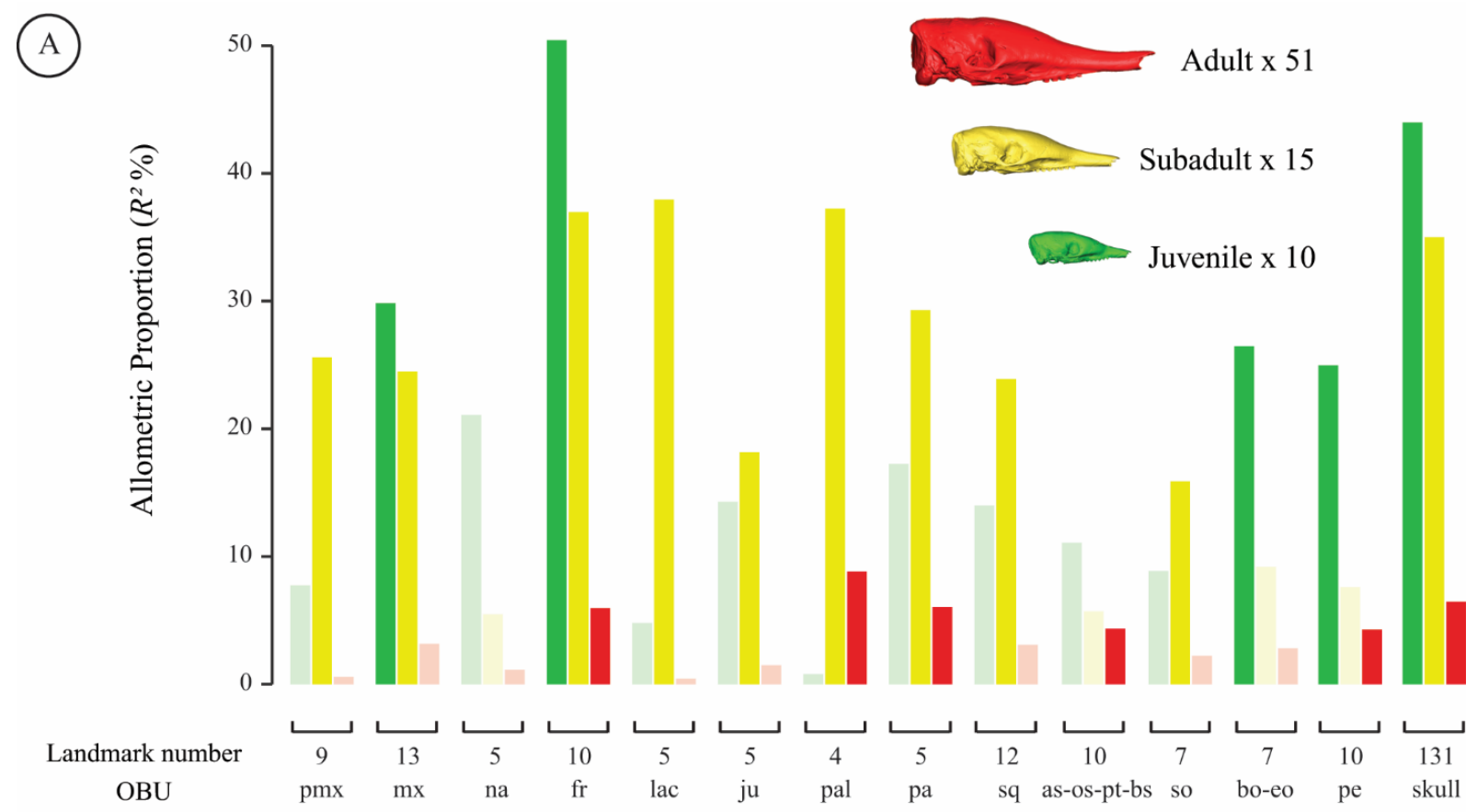

(B)

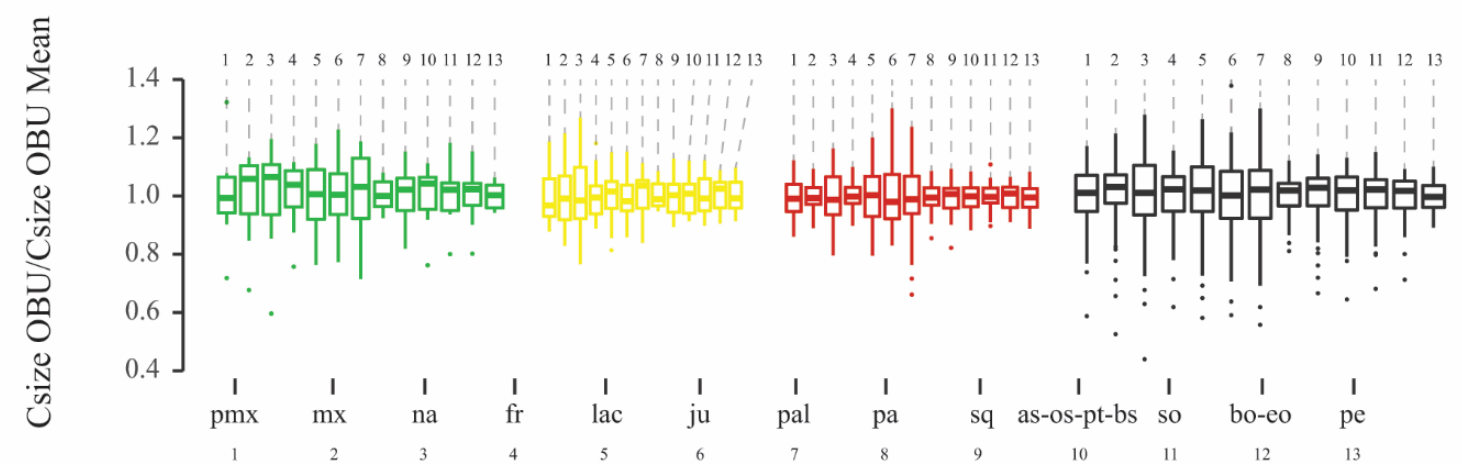

Figure 6. Allometry and growth pattern per cranial unit (OBU) and per postnatal ontogenetic stage. A) Bar graph showing the allometric proportions of shape variation per OBU and ontogenetic stage (see text). OBU caption is found in panel B. Bars with transparency indicate a statistically unsupported allometry for a given OBU and stage (at $p$ value $>0.05$ ) (see Table 4). B) Boxplot showing the variation of size for each OBU relative to its mean per stage (green, juvenile; yellow, subadult; red, adult), and for the whole sample (in black), as measured by the following ratio for every specimen: log OBU centroid size / mean log OBU centroid size at a given stage. Abbreviations of OBUs: as-os-pt-bs, alisphenoidorbitosphenoid-pterygoid-basisphenoid complex; bo-eo, basioccipital-exoccipital complex; fr, frontal; ju, jugal; lac, lacrimal; mx, maxillary; na, nasal; pa, parietal; pal, palatine; pe, petrosal; pmx, premaxillary; so, supraoccipital; sq, squamosal. 
(A)

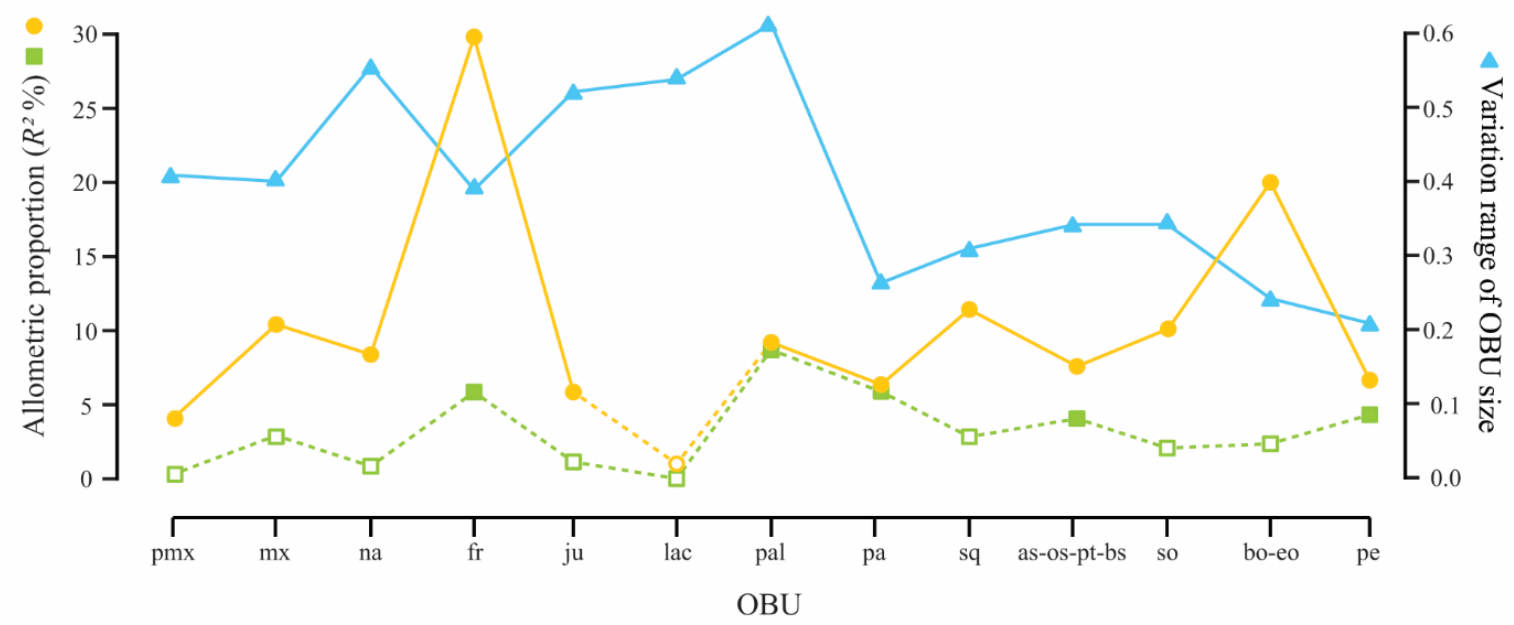

(B)

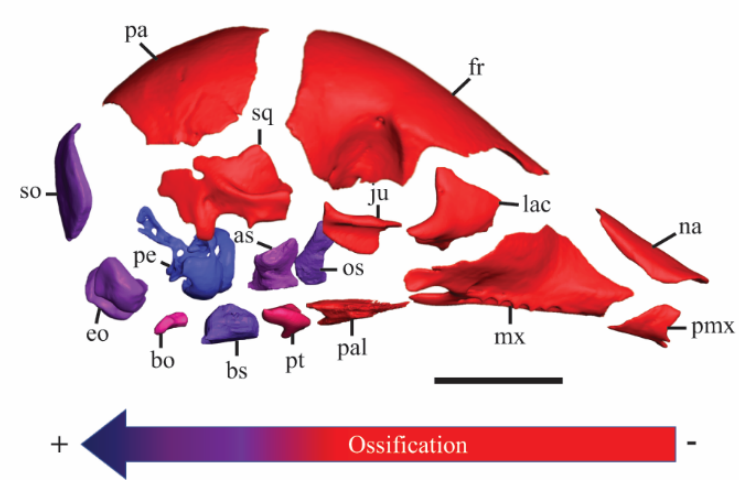

(C)

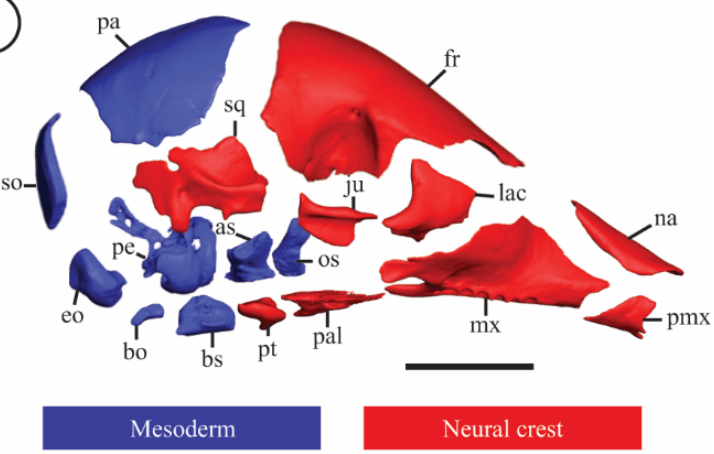

Figure 7. Comparison between the allometric proportion of shape variation, the variation in size and developmental characteristics for each cranial unit treated in this paper (see Discussion). A) Allometric proportions at ontogenetic (light orange circles) and static (light green squares) levels (unfilled figures correspond to non-supported allometric effects, see text) and variation range of each OBU's size around its mean (light blue triangles). The latter is calculated as the interval between the first and third quartile of the ratio used in Fig. $6 \mathrm{C}$, for the whole sample. B) Ossification chain according to Hautier et al. (2011). C) Distribution of embryonic origin of each bone according to Piekarski et al. (2014). Abbreviations: as-os-ptbs, alisphenoid-orbitosphenoid-pterygoid-basisphenoid complex; bo-eo, basioccipitalexoccipital complex; fr, frontal; ju, jugal; lac, lacrimal; mx, maxillary; na, nasal; pa, parietal; pal, palatine; pe, petrosal; pmx, premaxillary; so, supraoccipital; sq, squamosal. Scale-bar = 1 $\mathrm{cm}$.

\section{TABLE CAPTIONS}

Table 1. Definition of external landmarks. * Suture exoccipital/supraoccipital marks by a bulge in adult.

\begin{tabular}{cl}
\hline Number & Definition \\
\hline 1 & Most anterodorsal point of the internasal suture \\
2 & Intersection between internasal suture and frontal bone \\
$3-4$ & Intersection between midline and premaxillary/ maxillary suture \\
5 & Most posterior point of the premaxillary/maxillary suture on the palate \\
$6-7$ & Most anterior point of the premaxillary midline suture \\
8 & Most anterior point of the premaxillary/nasal suture \\
$9-10$ & Maximum curvature point between $\# 8$ and the anterior process of the premaxillary
\end{tabular}


13-14 Most anterior point of the premaxillary anterior process

15-16 Most anterior point of incisive foramen in strict ventral view

17-18 Most posterior point of incisive foramen in strict ventral view

19 Intersection between palatine/maxillary suture and the palate midline

20-21 Intersection between maxillary/palatine suture and lateral edge of palate

22-23 Intersection between jugal/maxillary suture and ventral edge of zygomatic arch

24-25 Most dorsal point of the maxillary foramen

26-27 Most dorsal point of the infraorbital foramen

Most anterior point of the alveolar margin of the premolar tooth row

Most posterior point of the alveolus margin of the premolar tooth row

Most posterior point of the palatine midline

Triple contact point between frontal/maxillary/nasal

Triple contact point between lacrimal/maxillary/frontal

Intersection between the lacrimal/frontal suture and the anterieur orbital edge

Anteroventral margin of the lacrimal foramen

Most dorsomedial point of the orbit (i.e., minimal interorbital length)

Triple contact point between squamosal/frontal/alisphenoid

Most anteroventral point of caudal palatine foramen (in lateral view)

Most anteroventral point of the sphenorbitaire fissure

Triple contact point between maxillary/jugal/lacrimal

Intersection between anterior orbital edge and jugal/lacrimal suture

Most dorsal point of the jugal/squamosal suture

Most ventral point of the jugal/squamosal suture

Most ventral point of the postglenoid process

Most posterodorsal point of the postglenoid foramen

Most posterodorsal point of the zygomatic ridge of the squamosal

Most dorsal point of the external acoustic meatus on squamosal (in lateral view)

Most posterior point of the small alisphenoid process delimitating the carotid notch laterally

Most anteroventral point of the transverse canal foramen

Most anteroventral point of the foramen ovale

Most posterior point of the alisphenoid/squamosal suture in front of pyriform fenestra

Most anterodorsal point of the optic foramen

Ventral tip of entoglenoid process

Intersection between frontal/parietal suture and the midline

Intersection between parietal/supraoccipital suture and the midline

Triple contact point between the frontal/squamosal/parietal

Triple contact point between the parietal/squamosal/supraoccipital

Most distal point of the supraoccipital on the midline (occipital face)

Most posterior point of the nuchal process of the supraoccipital

Most anterodorsal point of the sulcus for the occipital artery

Most lateral point of basioccipital/basisphenoid suture

Intersection between the anteromedial edge of occipital condyle and foramen magnum

Triple contact point between the supraoccipital/exoccipital/petrosal*

Most posterolateral point of the jugular foramen

Most posterolateral point of the hypoglossal foramen

Most anterolateral point of the occipital condyle (in ventral view)

Most anteroventral point of the foramen magnum

Most posterodorsal point of the foramen magnum

103-104

105-106

107-108 Most ventral point of external aperture of cochlear canaliculus

Most medial point of promontorium of petrosal in ventral view

109-110 Most anterior point of the fenestra vestibuli

$111-112$

Most anteroventral point of the external apertur of cochlear fossula

1180 Table 2. Definition of internal landmarks. * Landmark removed in 3B analyses. ** Projected 1181 landmark.

\begin{tabular}{cl} 
Number & \\
\hline 73 & Anteroventral tip of the tentorial process on the midline \\
113 & Dorsal intersection of annular ridge and midline \\
$114^{*}$ & Dorsal intersection between cribriform plate and median septum posterior to the latter \\
$115-116$ & Maximum curvature point of the lateral occipital ridge in caudal cerebral fossa \\
$117-118$ & Most dorsal point of the petrosal on the level of the crista tentoria transversally \\
$119-120$ & Most anteromedial point of the foramen acusticum superius \\
$121-122$ & Most anteromedial point of the foramen acusticum inferius \\
$123-124$ & Most anterior point of epitympanic wing of petrosal \\
$125-126$ & Maximum curvature point in the ventromedial area of the fossa subarcuata \\
$127-128$ & Most dorsal point of the internal posterior aperture of the optic canal
\end{tabular}


Table 3. Results of the multivariate regression for ES and 3B with log skull centroid size at the ontogenetic and static levels. Index: $a$, slope coefficient; Intercept; $R^{2}$, allometric proportion of shape variation; $p$-value, significance following the permutation test. The shaded lines correspond to the tests with a non-significant $p$-value $(>0.05)$.

Log Skull Centroid Size

\begin{tabular}{|c|c|c|c|c|c|c|c|c|}
\hline & \multicolumn{4}{|c|}{ Ontogenetic Level } & \multicolumn{4}{|c|}{ Static Level } \\
\hline & a & intercept & $R^{2}$ & $p$-value & a & intercept & $R^{2}$ & $p$-value \\
\hline Entire Skull & 0.2273 & -2.8776 & 0.27618 & 0.0001 & 0.2307 & -2.9312 & 0.06311 & 0.0001 \\
\hline Premaxillary & 2.6620 & -6.7570 & 0.04242 & 0.0054 & 2.3270 & -5.9140 & 0.00558 & 0.9774 \\
\hline Maxillary & 2.5780 & -6.5430 & 0.10665 & 0.0001 & 3.2890 & -8.3600 & 0.03148 & 0.1040 \\
\hline Nasal & 1.6900 & -4.2890 & 0.08368 & 0.0004 & 1.4820 & -3.7670 & 0.01127 & 0.6700 \\
\hline Frontal & 5.2690 & -13.376 & 0.29873 & 0.0001 & 5.1750 & -13.155 & 0.05965 & 0.0200 \\
\hline Lacrimal & 1.8680 & -4.7420 & 0.01568 & 0.2802 & 2.4230 & -6.1600 & 0.00429 & 0.9425 \\
\hline Jugal & 3.2730 & -8.3090 & 0.06006 & 0.0015 & 3.7490 & -9.5290 & 0.01476 & 0.5640 \\
\hline Palatine & 4.0190 & -10.202 & 0.09004 & 0.0006 & 9.7290 & -24.730 & 0.08829 & 0.0053 \\
\hline Parietal & 2.2530 & -5.7180 & 0.06661 & 0.0005 & 5.1620 & -13.121 & 0.06036 & 0.0120 \\
\hline Squamosal & 3.7480 & -9.5130 & 0.11490 & 0.0001 & 4.6370 & -11.787 & 0.03084 & 0.0875 \\
\hline As-Os-Pt-Bs & 3.8850 & -9.8610 & 0.07351 & 0.0001 & 7.4030 & -18.819 & 0.04347 & 0.0178 \\
\hline Supraoccipital & 3.5370 & -8.9790 & 0.10031 & 0.0001 & 4.0930 & -10.405 & 0.02223 & 0.3164 \\
\hline Bo-Eo & 4.7010 & -11.933 & 0.19612 & 0.0001 & 4.0220 & -10.223 & 0.02801 & 0.1756 \\
\hline Petrosal & 2.6430 & -6.7100 & 0.06281 & 0.0001 & 5.5540 & -14.119 & 0.04270 & 0.0242 \\
\hline
\end{tabular}

Table 4. Results of the multivariate regression for ES and 3B with log skull centroid size for each ontogenetic stage. Index: $a$, slope coefficient; Intercept; $\alpha^{*}$, angle of the slope with the horizontal axis in the common allometry analyses; $R^{2}$, allometric proportion of the shape variation; $p$-value, significance following the permutation test. The shaded lines correspond to the tests with a non-significant $p$-value $(>0.05)$.

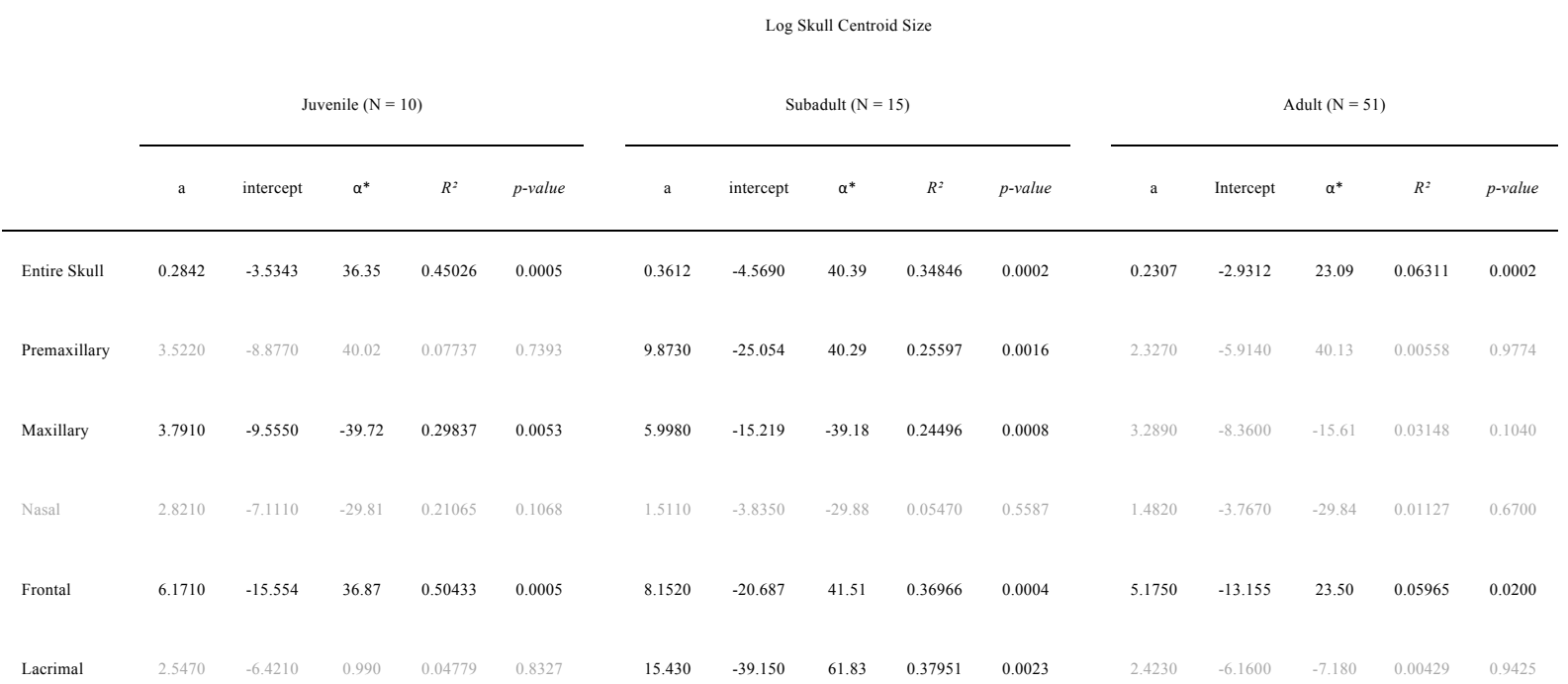




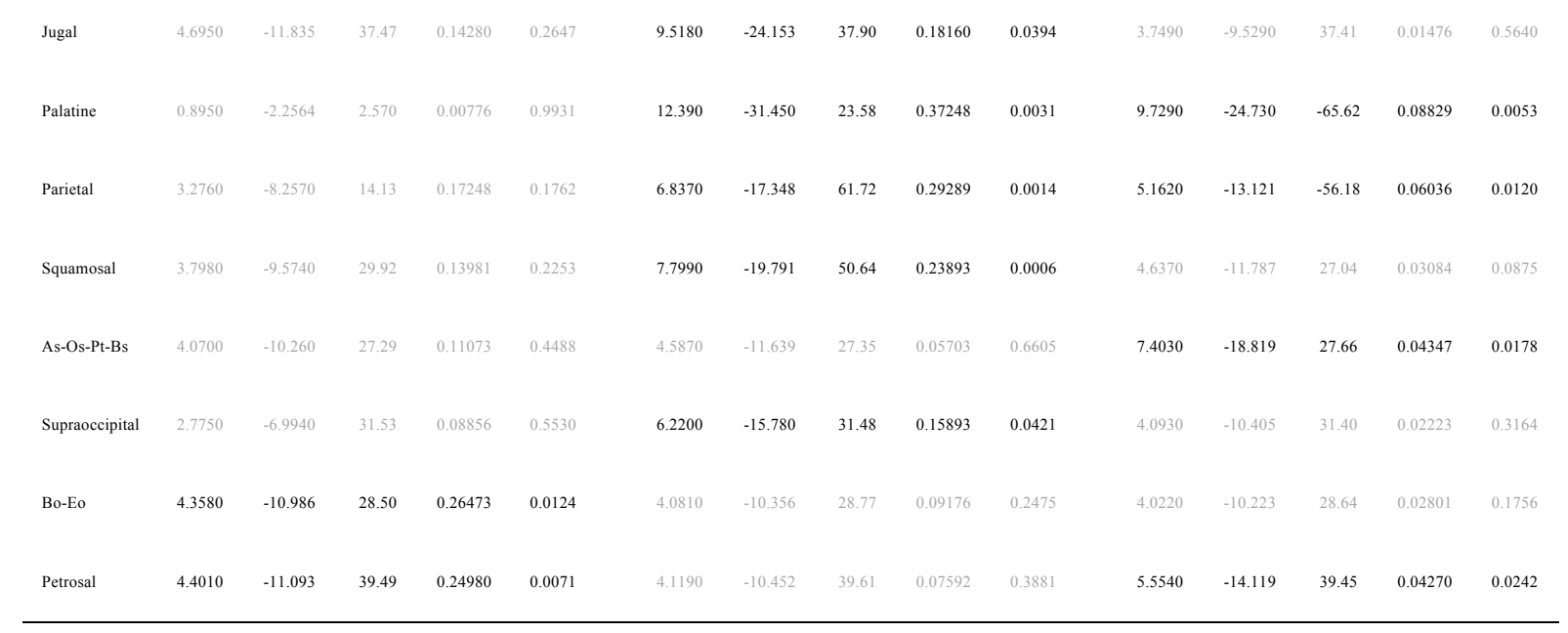
SUPPORTING INFORMATION

Supplementary Information 1. Protocol and results of the determination of ontogenetic stages.

Supplementary Information 2. Description of allometric variations of OBUs at the static level.

Only OBUs with statistically supported allometric variation are discussed in this document.

Figure S1. CT-scan sections representing the five dental stages defined in relation to the eruption of deciduous (dPM) and permanent teeth (PM). The analysed locus always corresponds to the $4^{\text {th }}$ premolar represented here by an arrow. Based on our observations of the upper dentition, we defined five dental stages: (1) dPMs starting to mineralize or erupting; (2) all dPMs well mineralized, possibly all erupted, no PM in the crypts (i.e., PM not mineralized); (3) all dPMs erupted, with part of the PMs mineralized but still in the crypts (not yet reaching the alveoli); (4) part of the dPMs about to be replaced by PMs (one or several PMs has/have erupted through the alveoli, but remain(s) almost unworn); (5) all PMs erupted and no remain of dPMs left (see Supplementary Information 1). 
Figure S2. Bivariate linear regressions among three dentary measurements and the LTC. A. With the height of the P4/dPM4. B. With the height of the alveoli of the PM4/dPM4. C. With the height of the growth front of the P4/dPM4. Each measurement is illustrated in the section to the right of each graph. For each simple regression, the slope equation, $R^{2}$, significance of the $t$-test and significance of the $F$-test are specified. In each case, specimens, whose dental stage (2 or 5) is unknown, were determined a posteriori (see Supplementary Information 1).

Figure S3. Ontogenetic stages determined based on dental eruption, as compared to the ossification score and the total length of the skull (LTC). The dental stages correspond here to: 1 , stillborn $(\mathrm{n}=1) ; 2$, juvenile $(\mathrm{n}=11) ; 3$, subadult $1(\mathrm{n}=7) ; 4$, subadult $2(\mathrm{n}=9) ; 5$, adult $(n=56)$. The black dots refer to specimens $(n=12)$ whose dental stage could not be determined. See Supplementary Information 1 for more detail.

Figure S4. Allometric trajectories among three nine-banded armadillo's morphotypes (Southern, Central and Northern) at ontogenetic (A - illustrated by juvenile and adult specimens in dorsal view) and static (B - illustrated by adult specimens in dorsal view) levels. The $y$-axis values are the principal component 1 of the predicted values of a multivariate regression of shape on size; the $\mathrm{x}$-axis values are the log-transformed skull centroid sizes for each specimen. For each level, the HOS test, Procrustes ANOVA and Pairwise comparisons of the allometric trajectory angles results are shown (in bold, the $R^{2}$ and $p$-value for the first two analyses and the angles between the slope and its intercept with a significant $p$-value). 
Figure S5. Vector representation in southern morphotype of the allometric shape changes detected for the entire skull and a given cranial unit (OBU), represented between its minimal (green - smaller centroid size) and maximal (red - larger centroid size) shape (see Fig. 2) with the associated $R^{2}$ and $p$-value. Results of the analyses performed at the ontogenetic level, and with the log skull centroid size taken as the size variable (see text). For each OBU, the changes are shown in one view with vectors from minimal to maximal shape with the minimal OBU shape shown in transparency. A) Entire skull in dorsal view. B) Entire skull in lateral view. C) Alisphenoid-orbitosphenoid-pterygoid-basisphenoid complex in dorsal view. D) Basioccipital-exoccipital complex in ventral view. E) Frontal in ventral view. F) Jugal in medial view. G) Maxillary in medial view. H) Nasal in ventral view. I) Palatine in dorsal view. J) Parietal in dorsal view. K) Petrosal in lateral view. L) Premaxillary in medial view. M) Squamosal in ventral view. N) Supraoccipital in occipital view. Landmark numbers and orientation arrows were added for more readability as well as the overall representation of the unpaired bones (basioccipital and supraoccipital). Abbreviations: A, anterior; D, dorsal; L, lateral; V, ventral.

Figure S6. Multivariate regression for each OBU at the ontogenetic level using log skull centroid size.

Figure S7. Multivariate regression for each OBU at the static level with log skull centroid size.

Figure S8. Vector representation of the allometric shape changes detected for a given cranial unit (OBU), represented between its minimal (green - smaller centroid size) and maximal (red - larger centroid size) shape (see Fig. 2). Results of the analysis performed at the static level, 
and with the log skull centroid size as the size variable (see text). For each OBU, the changes are shown in three subsections organized horizontally: 1, vectors from minimal to maximal shape with minimal OBU shape; 2, same as 1) with maximal OBU shape; 3, minimal OBU shape in transparency with vectors. A) Alisphenoid-orbitosphenoid-pterygoid-basisphenoid complex; A1-A2, dorsal view; A3, lateral view. B) Frontal; B1-B2, ventral view; B3, lateral view. C) Palatine; C1-C2, dorsal view; C3, ventral view. D) Parietal; D1-D2, dorsal view; D3, ventral view. Landmark numbers and orientation arrows were added for more readability. Abbreviations: A, anterior; D, dorsal; L, lateral.

\section{Figure S9. Common allometric analyses. Trajectories are derived from homogeneity of slope} test, plotting log transformed geometric means in the x-axis (i.e., log skull centroid size) and the $\mathrm{PC} 1$ of the predicted values of multivariate regression of shape ratios on size in the y-axis (Shape (Predicted)) (see Material and Methods).

Table S1. List of specimens.

Table S2. Landmark coordinates without treatment.

Table S3. List of landmarks placed on each of the 76 specimens, with a precision on the estimated landmarks (in red) (see Material and Methods).

Table S4. Measurements on the location of the P4, LTC and dental stages. * Specimen assigned to a dental stage a posteriori (see Fig. S2).

Table S5. Ontogenetic table with the ossification score, the dental score and LTC. 
1287 Table S6. Statistical results of the Procrustes ANOVA from the multivariate regressions at 1288 ontogenetic and static level for ES and 3B analyses with log skull centroid size (see Table 3).

1290 Table S7. Statistical results of the Procrustes ANOVA from the multivariate regressions for 1291 each ontogenetic stage for 3B approach using the log skull centroid size (see Table S4).

1292

1293 Table S8. Statistical results of the homogeneity of slope test between ontogenetic stages using 1294 the log skull centroid size (see Fig. S9). A significant $p$-value $(<0.05$ - unshaded line) implies 1295 that at least one of the groups has a different allometric trajectory from the others. 